\title{
6 The pair approach: what causes convergence of environmental policies?
}

\author{
THOMAS SOMMERER, KATHARINA HOLZINGER \\ AND CHRISTOPH KNILL
}

\section{I INTRODUCTION}

The central objective of this chapter is to assess the influence of three international mechanisms on the convergence of environmental policies in Europe, namely international harmonisation, transnational communication and regulatory competition. In so doing, we apply a novel concept - the pair approach - for measuring and explaining convergence.

In this chapter, three central research questions underlying this study are addressed. First, on the basis of the pair approach, we provide further insights into the extent of cross-national policy convergence, which complement the aggregate analysis in chapter 5 . Second, and this is the primary concern of this chapter, we investigate the specific impact of economic and institutional interlinkages between nation states on policy convergence. Third, and related to this point, we are interested in the explanatory relevance of possible alternative explanations (in particular domestic factors) that were introduced in the theoretical part of this book (chapter 3). In answering these questions, we merely concentrate on potential changes in the similarity of individual environmental policies and of policy repertoires of countries over time. The direction of convergence, i.e., movements to the top or to the bottom of regulation, is not the subject of the analysis in this chapter, but will be analysed in chapter 7.

Our analysis is based on the following steps. We first introduce the concept of the pair approach (section 6.2). The reasons for using 
this approach are given first, followed by a description of the calculation of pair similarity and convergence under this conception, and of the selection of policy items used for the dependent variable in the pair approach. Section 6.3 gives the descriptive results on policy convergence according to the measurement concept used for the pair approach. Section 6.4 specifies the independent variables used in the quantitative model, as well as the hypotheses to be tested in the pair approach. These hypotheses are precise formulations of the general expectations on causal relationships between the independent variables and the degree of policy convergence expressed in chapter 3 . Section 6.5 outlines the characteristics of the quantitative model. Finally, section 6.6 provides the findings of the regression analysis for the whole sample of environmental policies, as well as for some policy sub-groups that are of theoretical interest.

\subsection{THE PAIR APPROACH}

\subsubsection{Characteristics of the pair approach}

Some forms of sigma-convergence were already presented in chapter 5 , for example the coefficient of variation, adoption rates and box plot distributions. None of them, however, allows the testing of hypotheses on causal mechanisms at the country level, as they are aggregate descriptive measures of convergence. Therefore, it proved necessary to develop a more sophisticated measurement concept of sigma-convergence that can overcome the limitations of the measures used in chapter 5 .

The concept of policy convergence is based on the comparison of policy changes across a number of countries. Thus, the assessment of convergence requires a point of reference. An aggregate measure, such as the sample mean, can serve as the point of reference. However, if the analytical focus is on the degree rather than the direction of convergence the most direct approach is to compare each country to all other countries by way of a dyadic approach. This represents the lowest possible level of aggregation for any assessment of similarity. This way, no divergence or convergence shifts 
will be filtered out by reference to an aggregate figure. A pairwise comparison is the basic starting point for the study of sigmaconvergence. It is possible to extend the concept from dyads to triads and tetrads and so on, up to the level of the whole country sample in subsequent steps.

In the pair approach the units of analysis are country pairs and not single countries. Consequently, the concept of convergence implies an increase of policy similarity between a certain pair of countries over time. The use of country pairs or dyads is new to the study of policy convergence, whereas it is common in other research areas, e.g., in the study of international conflict (Bremer 1992; Hewitt 2003; Kinsella and Russett 2002). Barrios, Görg and Strobl (2003) is an example from the economic literature applying a similar approach to the study of convergence of firm types.

The pair approach is not only the most direct way to compare policy changes with respect to their divergence or convergence; it involves several additional advantages for the study of convergence. First, any movement of convergence or divergence between countries is taken into consideration. Second, it can be used for both categorical and metrical data, whereas the coefficient of variation can only be applied to metrical data. Thus, using the pair approach, the various dimensions of policies in our sample (presence-of-policy, instrument and setting/ can be integrated into one measure. Third, as it is not based on aggregate figures like the coefficient of variation, it allows for using a convergence variable instead of a similarity variable as the explanandum in a quantitative model. The variation coefficient is a measure of similarity at a given point in time, and not an appropriate measure of the development over time. Fourth, the hypotheses can be tested more directly with country pairs than at the level of individual countries: it is the common membership of a pair of countries in an international institution which is assumed to increase policy convergence among these countries via international harmonisation or via transnational communication. Likewise, it is the bilateral trade exchange that gives reason 
to assume that a pair of countries is exposed to regulatory competition. The whole quantitative model, that is, not only the dependent variable but also the independents, is based on country pairs. All variables are transformed to the pair level: the data set includes the common institutional membership of a certain pair, the bilateral trade exchange, a common border, a common language, and so on. The hypotheses specified in section 6.4 hence refer to country pairs; i.e., the more two countries are interlinked institutionally and economically, the more their policies will converge.

To be sure, there are also certain weaknesses inherent to the pair approach. At first glance, the logic of country pairs may not be intuitive to the reader. Methodologically, the pair approach may not be entirely independent from the composition of the sample: the score of a certain country pair can be determined by the score of other country pairs. However, this disadvantage also holds for other approaches, such as convergence towards the mean, because the comparison to a point of reference that is defined by the composition of the sample is immanent to the concept of convergence. Finally, the pair approach raises the number of cases from 24 countries to 276 country pairs. As the number of original subjects does not change, this increase may lead to overconfidence in the quantitative models. Therefore the significance of these models has to be interpreted carefully. Weighing up strengths and weaknesses, the pair approach offers the opportunity of an innovative and direct access to the study of sigma-convergence, measuring the increase or decrease of policy similarity between countries on the bilateral level.

\subsubsection{Selection of policy items for the dependent variable}

The dependent variable of the pair approach includes the whole policy repertoire of countries in our sample, i.e., all policy items introduced in chapter 4 . However, as the theoretical expectations outlined in chapter 3 vary for different policy sub-groups (e.g., trade-related versus non-trade-related policies| we complement the general dependent variable with a number of sub-group variables isee table A6.1 for a 
list of all policies and variables). This way we answer different research questions and obtain more robust estimations.

In the most encompassing variable all forty policies of the data set are included. The general variable aggregates presence-of-policy, policy instruments and policy settings. It comprises twenty-one setting items, twenty-eight policy instrument items as well as forty presence-of-policy items, which add up to eighty-nine items altogether. The difference in numbers has substantive reasons: while presence-of-policy applies can be assessed for all forty policies under investigation, this does not hold in a similar way for the instruments and settings. For example, for car emissions policy, it can be asked whether there is a policy present, which instrument is used (e.g., limit value), and finally, at which level the limit value is set. However, when the question is about the sustainability principle one cannot ask for the instrument or actual settings of limit values used, but only for its presence in laws. As a consequence, for each of the forty policies there is information in the data set on the presence of this policy in a certain country (yes-no), for twenty-eight policies there is information on the instrument used, ${ }_{1}^{1}$ and for twenty-one policies there is information on the precise setting of a value (limit value, tax rate).

We use the following sub-group variables. First, for each dimension of policy, there is a variable for presence-of-policy items, policy instrument items and policy setting items. This allows us to assess whether convergence effects are stronger with respect to the simple adoption of a policy and an instrument or with respect to a precise setting of the level of protection (see hypothesis 1 in chapter 3). Second, there is a variable for trade-related and non-trade-related

\footnotetext{
1 The questionnaire included twelve explicit questions for instruments; in five cases the question was followed by a settings question, in seven cases there was no settings question possible. However, we have additional implicit information on instruments, as for all settings policies we know automatically the instrument used. Thus, this adds up to twenty-eight policy instrument items itwenty-one settings plus seven pure instruments\}.
} 
policies within each sub-group. According to the theory of regulatory competition, convergence effects should be stronger for trade-related policies (see chapter 3). Third, we include in a similar way variables for obligatory and non-obligatory policies. The reason for this distinction is our theoretical expectation that the effects of international harmonisation on cross-national convergence should be more pronounced for obligatory measures, whereas for non-obligatory policies convergence effects should primarily be the result of transnational communication. Over time, the type of policy may shift from non-obligatory to obligatory, given respective harmonisation activities at the international level. Table A6.1 indicates at which point in time policies became obligatory.

\subsubsection{Calculation of pair similarity}

In order to measure policy convergence, in a first step the data set is transformed from the country level to dyads for each pair of countries. This way the number of cases extends from 24 countries to 276 country pairs. The number of combinations is calculated by the binomial coefficient, with double pairs (countries $A$ and $B$, countries $B$ and A) being eliminated, such that each pair is unique:

$$
\left(\begin{array}{l}
24 \\
2
\end{array}\right)=\frac{24 !}{2 !(24-2) !}
$$

In the raw data set, for the pair $\mathrm{AB}$ information on policy $\mathrm{X}$ is included for both countries separately. These two values are compared in order to calculate similarity scores. In table 6.1 the values for two policy items are given as examples: sulphur content in gas oil and the presence of bathing water policy for two points in time, 1990 and 2000. For instance, for Austria and Belgium, the respective values for the sulphur content in gas oil policies in the year 2000 are as follows: Austria: 0.10 limit value, 1: policy present and Belgium: 0.20 limit value, 1 : policy present.

The similarity scores are calculated as follows: the assessment of similarity is trivial for presence-of-policy items and for policy 


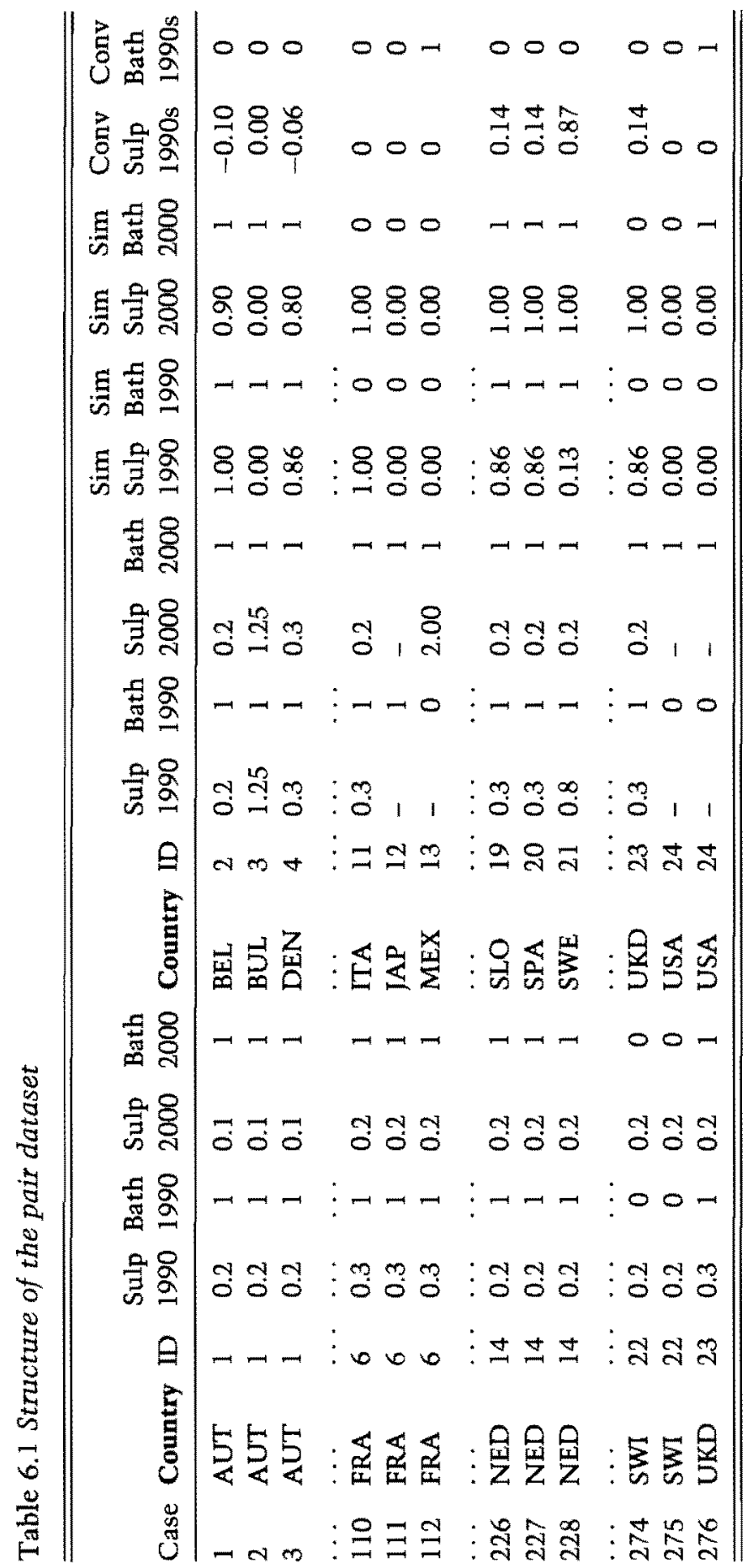


instrument items. When comparing the presence-of-policies and similarity of instruments, score ' 1 ' means that the countries A and $B$ have the same policy or the same instrument, whereas ' 0 ' means that they are dissimilar. Equations $|1\rangle$ and $|2|$ give this simple intuition formally:

$$
\begin{aligned}
& S P_{x, \underline{A B}}=1 \Leftrightarrow P_{x, A}=P_{x, B}>0 \\
& S P_{x, \underline{A B}}=0 \Leftrightarrow P_{x, A} \neq P_{x, B}>0 \\
& S I_{y, \underline{A B}}=1 \Leftrightarrow I_{y, A}=I_{y, B}>0 \\
& S I_{y, \underline{A B}}=0 \Leftrightarrow I_{y, A} \neq I_{y, B}>0,
\end{aligned}
$$

where $\mathrm{SP}_{\mathrm{x}}$ is the similarity of policy $\mathrm{x}, \mathrm{SI}_{\mathrm{y}}$ the similarity of instrument $y, P_{x}$ is the presence-of-policy $x$ and $I_{y}$ the instrument $y_{\text {, }}$ and $A B$ the dyad of countries $A$ and $B$.

For setting items, by contrast, we apply a normalised metrical score from 0 to 1 based on differences between limit values of country $A$ and $B$, leading to a similarity scale between 1 limit values are identical) and 0 (country pair with the most dissimilar setting values). For all other values gradual similarity is assessed by weighting the distance between two settings with the maximum distance for each item and for each point in time. The maximum distance is controlled for outliers by calculating the range between the 90 per cent and the 10 per cent quantile of the empirical distribution. Again, this is formalised in equation (3):

$$
S S_{z, \underline{A B}}=1-\frac{\left|S_{z, A}-S_{z, B}\right|}{S_{z, 90}-S_{z, 10}},
$$

where $\mathrm{SS}_{z}$ is the similarity of setting $z, S_{z, A}$ and $S_{z, B}$ the level of policy setting $z$ for countries $A$ and $B$ and $S_{z, 90}$ and $S_{z, 10}$ the 90 per cent and the 10 per cent quantile of the empirical distribution of setting $z$ in the sample.

As already mentioned, we analyse not only the whole sample of forty policies, but also different sub-groups. For the presenceof-policy, the instrument and the setting items, as well as for 
all sub-groups of them (see table A6.1) the scores are simply summed up for the respective policy items included. For example, if the dependent variable consists of all twenty-one setting items a maximum score of 21 can be reached by a country pair, in case of all presenceof-policy items the maximum score is 40 , in case of trade-related settings the maximum score is 16 , etc.

For the encompassing general dependent variable that includes all policies and all dimensions of policies (presence, instrument and setting), the similarity scores across all forty presence-ofpolicy, twenty-eight instruments and twenty-one settings are summed up. We thus arrive at a similarity scale from 0 to 89 points. For better interpretation and for reasons of comparability with other scales, all scores are transformed to percentage scales, with the maximum of $89(40,28,21)$ points corresponding to 100 per cent similarity of environmental policies. An important aspect of the procedure of summing up over the policy items is that it introduces a second dimension to policy similarity: we learn not only about the similarity of single policies across countries but also about the similarity of the whole environmental policy repertoire across countries.

One important methodological point related to the rating of country pairs needs to be mentioned here: in constellations in which neither of the two countries of a pair had adopted a policy, instrument or setting, the countries are - by definition - treated as dissimilar, as we do not observe ' 0 ' on both sides, but an 'empty set' that cannot be compared. ${ }^{2}$ In the case of settings, it does not seem logical to assign the same maximum score (full similarity $=1$ ) to a pair of countries that both have no limit value and to a pair of countries that have adopted exactly the same limit value. In table 6.1, for instance, neither Switzerland nor the US had adopted a policy

\footnotetext{
${ }^{2}$ If a policy were abolished in both countries, then non-existence of policy would be interpreted as similarity. Empirically, however, such a case does not appear in our data set.
} 
on bathing water in 1990. They are hence given a similarity score of 0 on that policy. A consequence of this decision is that we might overestimate convergence effects for the early periods under investigation, as there are a number of countries that had not adopted many environmental policies in 1970 .

Notwithstanding this problem, however, the analysis of our data strongly supports our methodological decision. Table 6.2 shows that defining non-existent policies in a country pair as similarity leads to similarity scores that do not allow for a meaningful interpretation of the data. The table gives the results of the pair approach for policy similarity and policy convergence for presence-of-policy items. Two versions are compared: in version 1 country pairs which do not yet have a policy are rated as dissimilar, while in version 2 they are rated as similar. Whereas there is a clear increase in similarity over time and thus convergence in version 1, similarity in version 2 stays roughly the same over the three decades or even decreases. Thus, version 2 implies a strong overestimation of similarity in the early periods, which is a consequence of the fact that in 1970 most countries had not yet adopted many environmental policies. Rating them as similar in this respect clearly disturbs the estimation of the convergence movements: converging or diverging moves disappear in the aggregate perspective although they are present at the micro level.

Table 6.2 Policy similarity and policy convergence: mean values in $\%$ from different analytical perspectives

\begin{tabular}{|c|c|c|c|c|c|c|c|}
\hline & \multicolumn{4}{|c|}{ Policy similarity } & \multicolumn{3}{|c|}{ Policy convergence } \\
\hline & 1970 & 1980 & 1990 & 2000 & 1970 s & $1980 \mathrm{~s}$ & $1990 \mathrm{~s}$ \\
\hline $\begin{array}{l}\text { Presence-of-policy - } \\
\text { Version } 1\end{array}$ & 0.03 & 0.12 & 0.30 & 0.65 & 0.09 & 0.20 & 0.51 \\
\hline $\begin{array}{l}\text { Presence-of-policy - } \\
\text { Version } 2\end{array}$ & 0.82 & 0.73 & 0.67 & 0.74 & -0.09 & -0.06 & 0.07 \\
\hline
\end{tabular}




\subsubsection{Calculation of policy convergence}

The similarity scores are of particular interest for the descriptive analysis of environmental policies at one point in time. The main research questions of the project, however, deal with convergence, i.e., increasing similarity over time. Therefore, for the regression analysis of the effects of causal factors on convergence, the dependent variable should include information on convergence over a given period, not on similarity at a given point in time.

The similarity scores developed in the last section can easily be transformed to convergence scores. Convergence is measured by changes in percentage points of absolute similarity between $t_{0}$ and $t_{1}$, as expressed in the following equation:

$$
\begin{aligned}
& C P_{x \Delta t_{1}, \underline{A B}}=S P_{x, t_{1} ; \underline{A B}}-S P_{x, t_{0} ; \underline{A B}} \\
& C I_{y \Delta t_{1}: \underline{A B}}=S I_{y, t_{1}: \underline{A B}}-S I_{y, t_{0}: \underline{A B}} \\
& \mathrm{CS}_{z \Delta \mathrm{t}_{1} ; \underline{A B}}=\mathrm{SS}_{z, \mathrm{t}_{1}: \underline{A B}}-\mathrm{SS}_{z, \mathrm{t}_{0} ; \underline{A B}}
\end{aligned}
$$

where $\mathrm{CP}_{\mathrm{x}}$ is the convergence of policy $\mathrm{x}, \mathrm{CI}_{\mathrm{y}}$ the convergence of instrument $y$ and $\mathrm{CS}_{z}$ the changes in similarity scores of setting $z$;

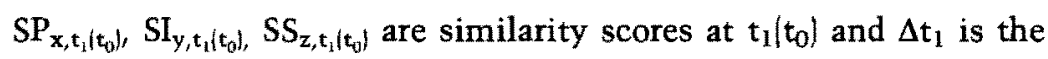
period between $t_{0}$ and $t_{1}$. To give an example, table 6.1 shows a strong increase in similarity between the Netherlands and Sweden during the 1990s (0.87) for sulphur content in gas oil.

For the aggregated convergence variables comprising groups of policy items, changes in similarity scores are summed up such that

$$
\begin{aligned}
& \sum_{x_{1}}^{x_{n}} C P_{\mathbf{x}_{i}, \Delta t_{1}: \underline{A B}}=\frac{\sum_{x_{1}}^{x_{n}} S P_{\mathbf{x}_{i}, t_{1}, A B}-S P_{x_{i}, t_{0}, \underline{A B}}}{n-k} \\
& \sum_{y_{1}}^{y_{n}} C I_{y_{i}, \Delta t_{1} ; \underline{A B}}=\frac{\sum_{x_{1}}^{y_{n}} S_{y_{i}, t_{1} ; \underline{A B}}-S_{y_{1}, t_{0}, \underline{A B}}}{n-k} \\
& \sum_{z_{1}}^{z_{n}} C_{z_{i}, \Delta t_{1}: A B}=\frac{\sum_{z_{1}}^{z_{n}} S S_{z_{i}, t_{1}, \underline{A B}}-S S_{z_{i}, t_{0}, \underline{A B}}}{n-k}
\end{aligned}
$$


where $n$ is the size of the sub-group of policies $x_{i}$ instruments $\mathrm{y}_{\mathrm{i}}$ and settings $z_{\mathrm{i}}$, and $k \in[1,2, \ldots i, \ldots n\}$ is the number of policies, instruments, or settings with $\mathrm{SP}_{\mathrm{x}_{\mathrm{i},} \mathrm{t}_{0 ;}, \mathrm{AB}}=\mathrm{SP}_{\mathrm{x}_{i}, \mathrm{t}_{1}, \mathrm{AB}}=1$

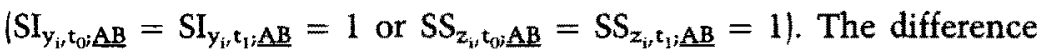
is weighted not by the number of policy items but with the factor $1 /(n-k)$. Those policy items that have shown complete similarity between $t_{0}$ and $t_{1}$ for country pair $\underline{A B}$ are excluded from a policy sub-group. This operation avoids the inclusion of saturation effects, which would imply an underestimation of convergence. For example, imagine a country pair that has a high degree of totally similar policies in $t_{0}$ that stay stable until $t_{1}$ : there is no possibility for convergence on these items any more. If the number of policies $n$ were not corrected by $k$, a larger denominator in equation (5) would decrease convergence rates for the respective period.

\subsection{DESCRIPTIVE ANALYSIS OF THE DEPENDENT VARIABLE}

The pair approach produces measures of policy similarity and policy convergence which are introduced into the explanatory model later on. However, the first result of the application of the pair approach is an aggregated version of the dependent variable. Thus, the pair approach provides also answers to the first research question of the project: To what extent can we observe convergence of environmental policies in Europe? In this section some important descriptive results are presented which complement the analysis given in chapter 5 . The following figures and tables show patterns of convergence at various levels of aggregation. Since for the basic levels of analysis it is impossible to present the complete results, section 6.3 .1 starts with the selective presentation of several policy setting examples and aggregate variables. Section 6.3.2 gives an overview on similarity and convergence of all policy groups. 


\subsubsection{Graphical display of pair similarity}

The most basic level of analysis is the similarity of country pairs with respect to single policies. Figure 6.1 uses 'limit values for lead in petrol' as an example of a policy. The graph displays the development of similarity between country pairs from 1970 to 2000 . The percentage scale relates to the maximum similarity score as outlined in the previous section. The graph shows five selected country pairs representing different developments: three pairs that converge, one pair that converges with divergence in between and one pair without significant convergence.

The country pair Switzerland and UK starts in 1970 already with some similarity ( 20 per cent), then shows a strong increase in similarity during the 1970 s and a slight increase during the 1980 s,
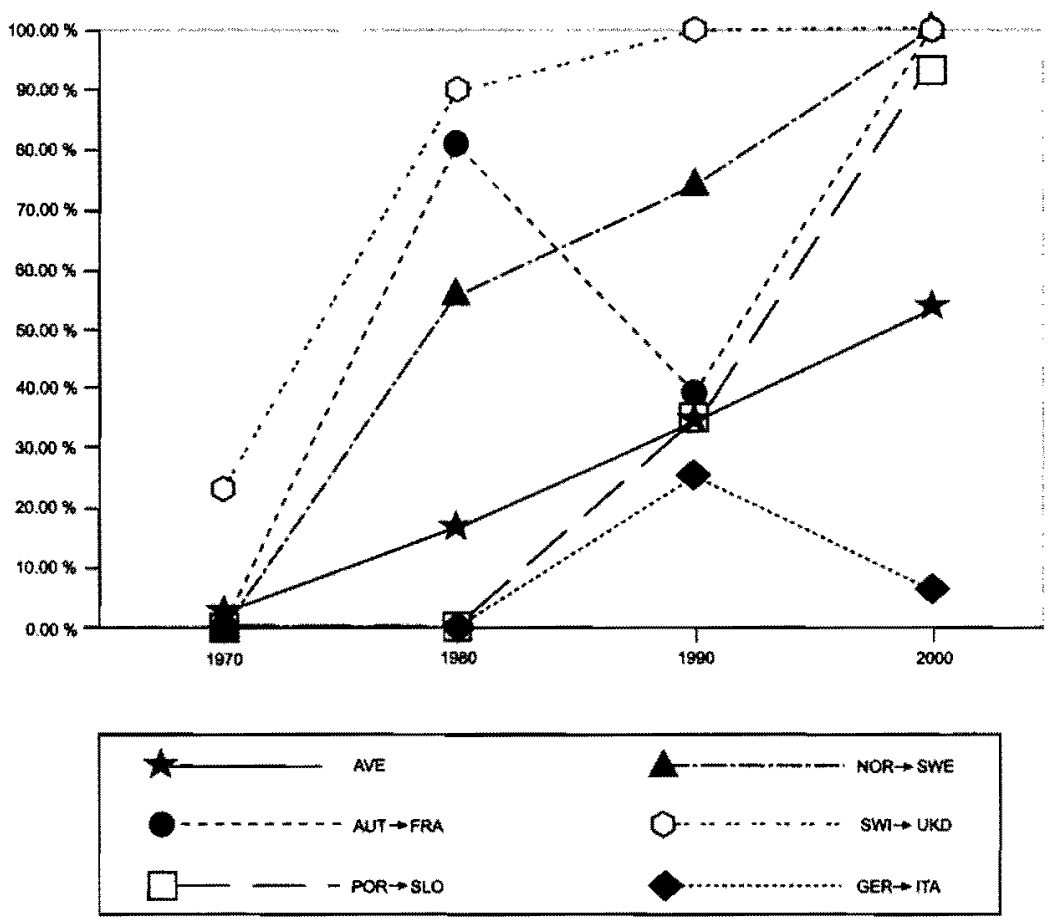

Figure 6.1 Similarity of selected country pairs, 1970-2000, limit values for lead in petrol 
reaching perfect similarity already in 1990 . Norway and Sweden, both having no policy in 1970, converge strongly during the 1970s. This approximation continues over time until they reach total similarity of their limit values in 2000. Portugal and Slovakia had dissimilar policies during the 1970s, converged slightly during the $1980 \mathrm{~s}$, and have almost the same policy in 2000. Austria and France reach already high similarity during the 1970 s, but they diverge significantly during the 1980s. A closer look at the data reveals that this divergence occurred although both countries strengthened their policies during that period; however, Austria did so to a much higher degree. In 2000, this pair ends up with identical limit values (100 per cent similarity). Finally, Germany and Italy do not show a significant pattern of convergence. Whereas in 1990 their limit values are modestly similar ( 27 per cent), they become almost totally dissimilar again during the $1990 \mathrm{~s}$, due to a unilateral strengthening of the German limit value.

Additionally, figure 6.1 gives the development of the 'average country pair' (the solid line). The average country pair is a first way of aggregation, as it represents the similarity of all 276 country pairs with respect to a certain policy. The average country pair shows a strong increase in similarity, starting with 2 per cent similarity in 1970 and ending up with 55 per cent in 2000 . 'Lead in petrol' is a policy with very clear convergence over the observation period.

There are other setting items that show a similar trend. Figure 6.2 shows convergence trends for lead in petrol, $\mathrm{CO}$ emissions from passenger cars and industrial discharges of zinc into surface water. While we can observe similarity increases for all of these items during the observation period, both similarity levels and similarity changes differ across policies and over time. Whereas in the case of $\mathrm{CO}$ emissions, the average pair reaches a similarity degree of 42 per cent in 2000, respective figures for zinc discharges in surface water only reach a level of 28 per cent. The preliminary explanation for this difference is the existence of harmonised EU standards for lead in petrol (Directive 78/611) and CO emissions (Directive 70/220). 


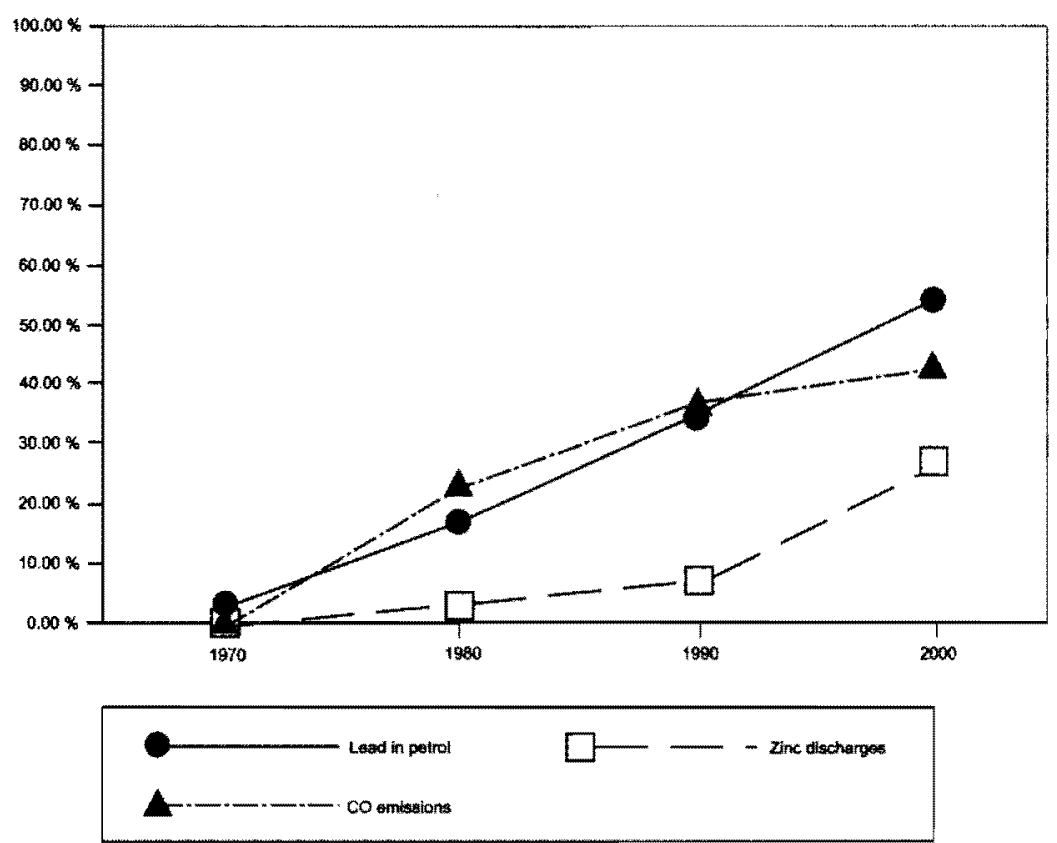

Figure 6.2 Similarity of average country pairs for selected policies, $1970-2000$

For zinc discharges, international harmonisation is completely lacking. Nevertheless, this item reveals at least some convergence.

The second form of aggregation is the summation of similarity scores of country pairs over all policies. Figure 6.3 illustrates convergence trends of five selected country pairs as well as the development of the average pair. The graph shows a permanent increase of average similarity of all country pairs over time, with slight convergence during the 1970 s and stronger convergence during the last decade, implying that in 2000 , the average country pair reaches the level of 56 per cent similarity. Having a reputation for early and strict environmental regulation, the pair Japan/Sweden has been the most similar pair in 1970 as well as in 1980 . In 1990 and 2000 , by contrast, the pairs with the highest similarity are Germany/Switzerland and Denmark/Netherlands. Moving from single policies to the aggregate 


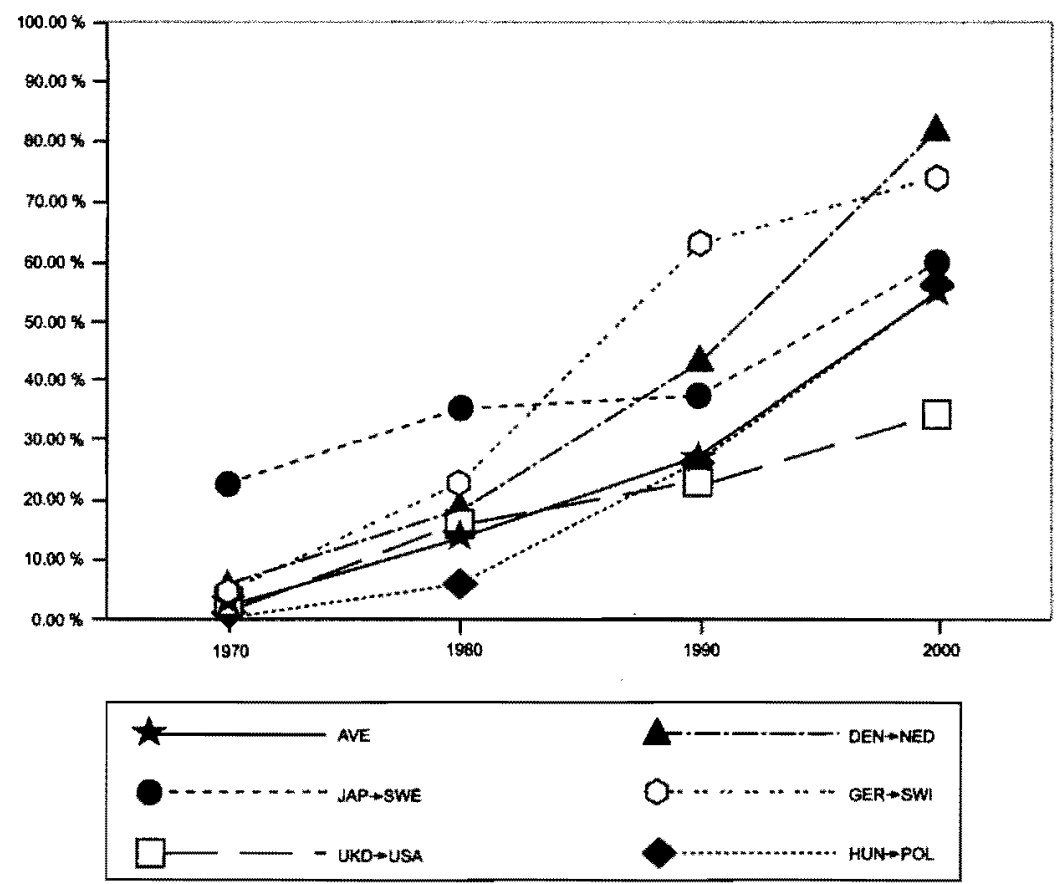

Figure 6.3 Similarity of the average pair and selected country pairs, 1970-2000, all policy items

level of all policies under investigation, the overall impression of a manifest convergence trend is quite obvious.

As not all country pairs can be displayed in one diagram, figure 6.4 summarises policy similarity of all policies and all country pairs for each point in time from 1970 to 2000 . It illustrates the distribution of all country pairs around the average pair. While the average pair reaches a similarity degree of 56 per cent, the pair with maximum similarity in 2000 reaches 82 per cent, and the minimum pair a value only slightly above 20 per cent. What can be observed is that the dispersion of values around the average (in particular, for the 25 per cent and 75 per cent quantiles) increased until 1990 and decreased during the last ten years. Thus, we observe a clear general convergence trend over the whole policy sample and the whole period. 


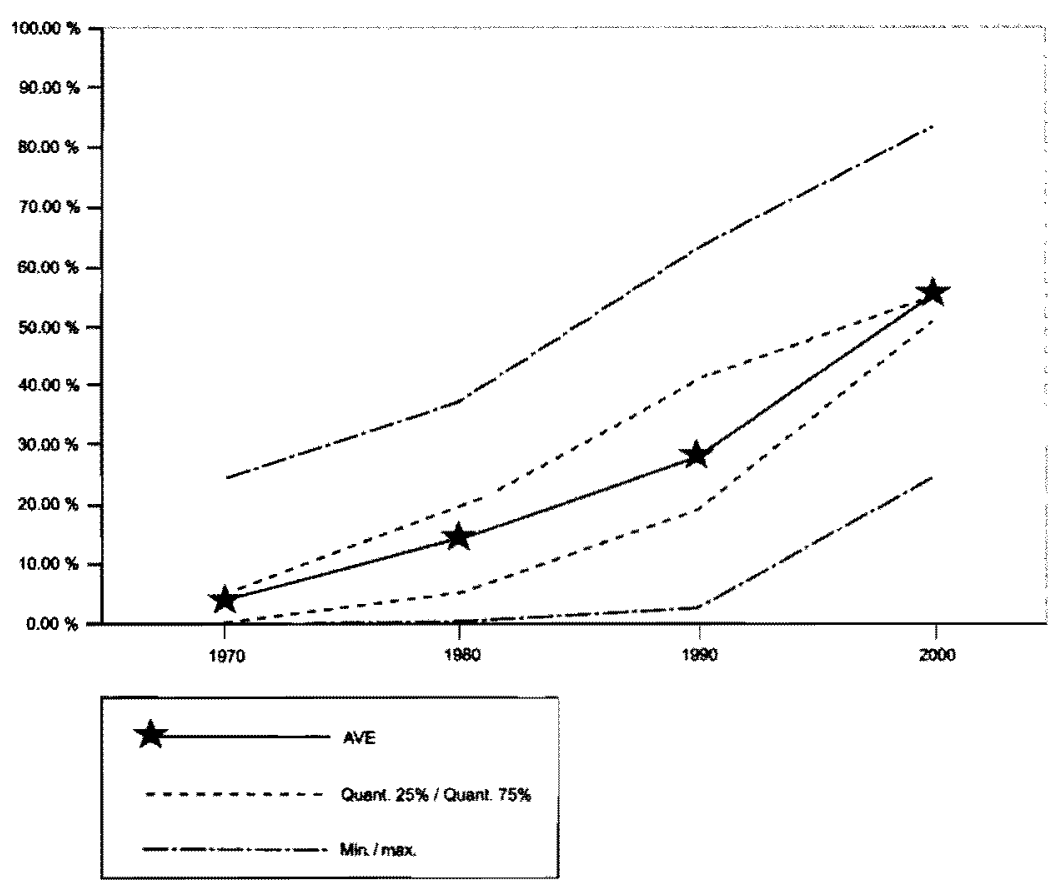

Figure 6.4 Similarity of the average, minimum and maximum pairs, 1970-2000, all policy items

\subsubsection{Mean values for policy similarity and policy convergence} An overall summary of the descriptive findings for all dependent variables that will be used in the regression analysis is presented in table 6.3. The table provides results for the whole sample used in the pair approach and for all policy sub-groups. It gives information about mean values of policy similarity for 276 country pairs in per cent) with respect to four points of time (1970, 1980, 1990 and 2000). Additionally, the results for similarity increases, i.e., policy convergence, between these points are provided. The last column gives the convergence results for the average of all three decades.

Several findings seem of particular interest. First, in general, similarity grows considerably from 1970 to 2000 (from 0.04 to 0.56 ). Moreover, we observe an increase of similarity from 1970 to 2000 not only for all items but also for all sub-groups of items. Second, 


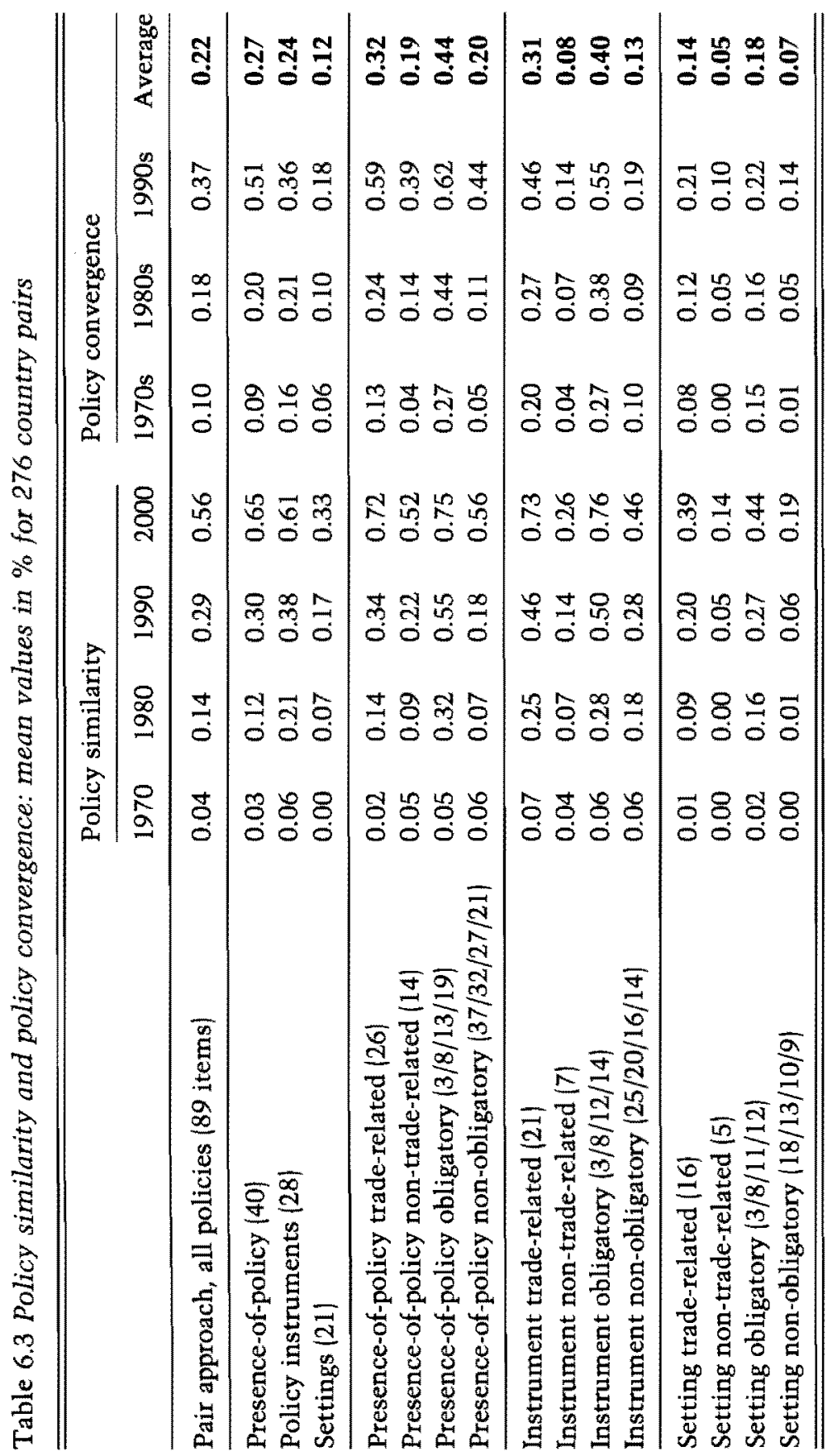


convergence effects are highest during the 1990s (0.37). Third, in 2000 similarity effects are most pronounced with regard to presence-ofpolicy items $(0.65)$ followed by instruments $(0.61)$, with settings being least developed $(0.33)$. The picture is similar for policy convergence laverage: $0.27,0.24 ; 0.12$ ). Fourth, when looking at policy types, it becomes apparent that similarity increases for trade-related policies are more pronounced than for policies not related to trade. A similar statement applies to the distinction between obligatory and nonobligatory items, with similarity effects being generally stronger in the former case. The highest rate of convergence across all policy groups is found for obligatory presence-of-policy items (average: 0.44 ), while the respective figures are lowest for non-obligatory settings (average: 0.07 ).

All of these results are in line with our theoretical expectations formulated in chapter 3 . We expected lower similarity increases, the more specific the policy dimension under investigation. Expected convergence is most pronounced for presence-of-policy and least for settings, with instruments lying somewhere in between. We also hypothesised that as a result of regulatory competition, convergence on trade-related policies should be higher than for policies not related to trade. Moreover, effects of international harmonisation should lead to higher convergence for obligatory items than for non-obligatory policies.

The overall picture of convergence is the result of aggregation: table 6.3 presents the mean values for 276 country pairs aggregated over a group of policies. Among them, of course, are also pairs that diverge for a certain policy in a given decade. However, there are not so many of such instances of divergence. Table 6.4 shows the number of items for which divergence occurred, distinguishing between different policy dimensions and observation periods. Divergence happens more often with setting and instrument items than with presence-ofpolicy items. This is not surprising as the setting items are much more specific than the presence-of-policy items which are based on a yes/no scale. Furthermore, in table 6.4 the diverging pairs are compared to the converging pairs. The share of converging pairs clearly 


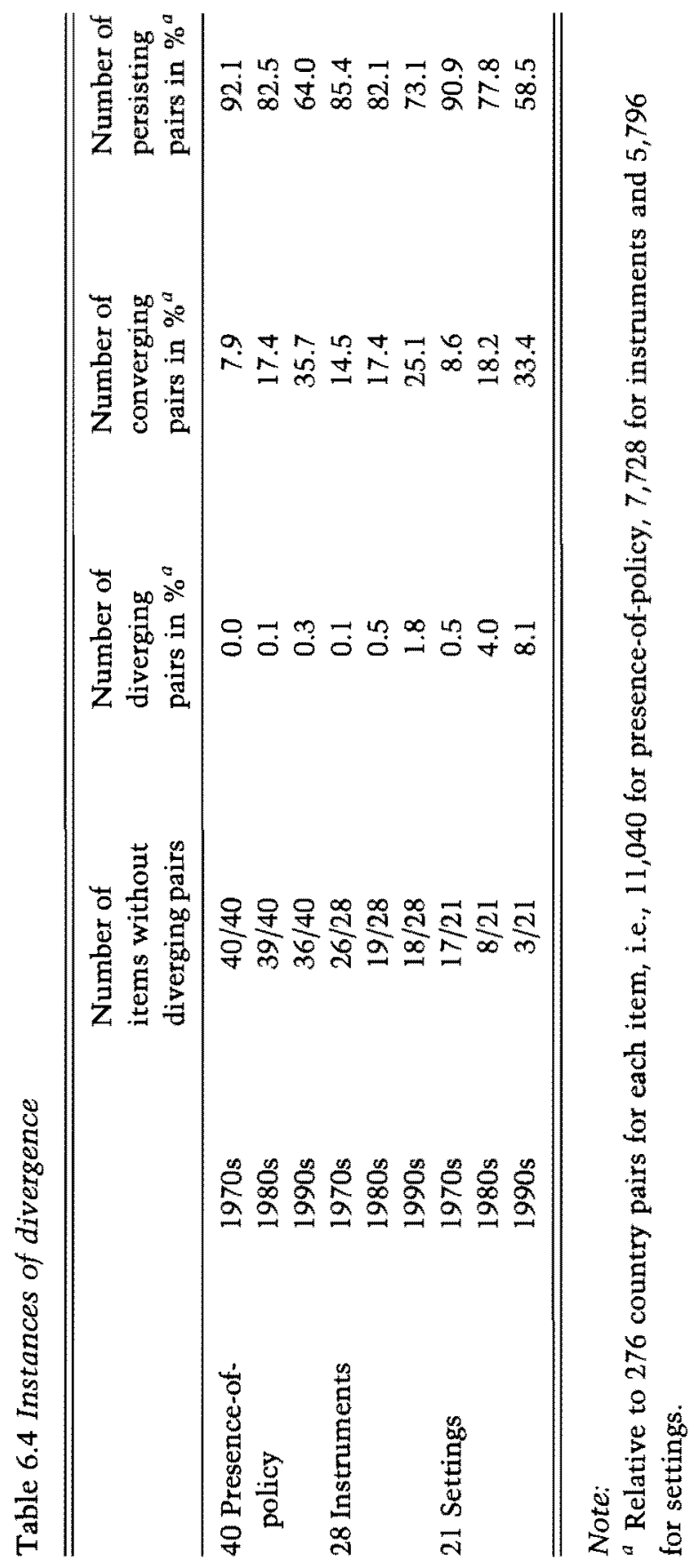


outnumbers the share of diverging pairs for all decades. Most pairs, however, do not move at all. The share of persisting pairs decreases significantly over time. The table shows that this is predominantly a result of increasing convergence, not of increasing divergence.

\subsection{INDEPENDENT VARIABLES AND HYPOTHESES}

After having elaborated on the measurements of convergence and the descriptive findings of the pair approach, we now turn to the question of theoretical explanation. For this purpose, we first have to specify the operationalisation of the independent variables under study in a way that makes them suitable for the pair approach. On this basis, we are also able to specify the general hypotheses formulated in chapter 3 for the analysis of country pairs. These adjustments are necessary since for the pair approach all variables are based on dyadic data, e.g., the common membership in institutions. Similarly, the hypotheses relate to country pairs and will thus be reformulated in order to fit the pair approach. The same numbering system will be used in order to allow identification easily.

The dependent variable used in the explanatory models is the convergence of policies, not their similarity at one point in time; i.e., we use the 'change rate' figures given in the right half of table 6.3. Policy convergence in each period of observation will be explained by independent variables that refer not to change rates but to absolute figures at the beginning of the decade. These are conceived as 'potentials' that are supposed to cause convergence in the following years, such as communicative potential through membership in international institutions or cultural similarity.

\subsubsection{International harmonisation}

The effects of international harmonisation land also transnational communication) as a causal mechanism of cross-national policy convergence are based on the impact of international institutions. To grasp these effects, we rely on an indicator of institutional interlinkage that is built on a sample of thirty-five institutions (see 
table A4.4 in the annex). We distinguish two types of international institutions relevant in the field of environmental policy: international environmental organisations, treaties, protocols or regimes (hereafter 'international institutions') and the EU.

The harmonisation effects of international institutions arise from accession: members ratify the treaty and have to comply immediately. This implies that convergence effects from accession occur only once. While such 'harmonisation effects through accession' are also given for the EU it also has 'harmonisation effects through membership': the institution continuously produces regulatory output that is directly legally binding on its member states. This leads to enduring and steadily renewed harmonisation effects. Hence, in contrast with accession effects EU membership in $t_{0}$ will imply convergence in subsequent periods.

To measure the effect of institutional harmonisation, we distinguish between three variables to cover both 'membership effects' and 'accession effects'. The first variable refers to convergence effects of membership in international institutions with obligatory potential. From the international institutions relevant in the environmental field, only the EU has this opportunity of internal harmonisation by adopting rules that are obligatory for its members. ${ }^{3}$ Hence, we use a dummy variable of common EU membership of a country pair to test the following hypothesis / this and the next two hypotheses are specifications of hypothesis $\mathrm{H} 2.1$ developed in chapter 3):

(H 2.1.1): If two countries are members of the EU in to, the environmental policies of both countries will converge in the following periods.

As already mentioned, the EU may also cause harmonisation through accession. To distinguish these effects from accession effects of other international organisations and regimes, we include a second dummy

\footnotetext{
Internal decisions of other intemational institutions, e.g., conference or party
} decisions, do not have an equivalent status in terms of international law. 
for the common accession to the EU of a country pair. As date of accession we use the beginning of the accession talks, as usually the candidate country already begins with the adoption of the acquis communautaire at that point in time.

(H 2.1.2): If one or both countries of a pair accede to the EU from to to $t_{1}$, such that both are EU members afterwards, the environmental policies of both countries will converge during the same period.

The treatment of EU membership and accession to the EU as separate variables can also be justified on the grounds that the EU could be expected to play a dominant role in the convergence of environmental policies in Europe. It is thus useful to be able to single out $E U$ effects from the effects of other intemational institutions.

The third variable takes account of the effects of accession to other international institutions. To measure these effects, we collected data on the membership of countries in the above-mentioned thirty-four international organisations and regimes (thirty-five minus EU). The common membership score is weighted by the institutions' encompassingness and obligatory potential. Changes of the score between $t_{0}$ and $t_{1}$ are taken as a proxy for convergence effects through accession to international institutions. The exact calculation of the indices can be found in table A4.3 in the annex.

(H 2.1.3): The higher the score of common institutional accession (weighed by obligatory potential) of a country pair from to to $t_{1}$, the more the environmental policies of both countries will converge during the same period.

\subsubsection{Transnational communication}

Potential effects of international institutions on the convergence of national policies are not restricted to the adoption of legally binding rules. Rather these institutions represent an arena for communication and information exchange among their members - an aspect that can trigger cross-national convergence by itself and independent of 
an institution's regulatory output (see chapter 3). The institutional influence that exceeds effects of harmonisation is included in the variable 'institutional membership'. With this variable, we grasp effects of membership in international institutions in to on policy convergence between $t_{0}$ and $t_{1}$. This is based on the assumption that convergence effects emerging from transnational communication will not unfold immediately with accession, but become relevant only after a certain period of membership. The variable consists of common membership data for all (including EU) international institutions, weighted by encompassingness, the length of membership and the institutions' communicative potential (see table A4.3 for details).

(H 3.1): The higher the score of common institutional membership (weighed by communicative potential) of a country pair in $t_{0}$, the more the environmental policies of both countries will converge in the following periods.

\subsubsection{Regulatory competition}

Theories of regulatory competition commonly refer to trade figures as a proxy for the economic interlinkage between countries. Trade flows are usually captured by an index of trade openness. For the pair approach, a different type of trade data is used, namely bilateral trade flows (see chapter 4 for details). As for other indices of openness, the trade volume is weighted by the size of the national economy. We apply the GDP of the smaller market in order to operationalise more precisely the dependence on international trade. Using bilateral data, the competitive situation between two national economies can be better captured. We include only trade flows between market economies, as trade between non-market economies (e.g., CEE countries before 1989) is not expected to unfold the effects focused upon by theories of regulatory competition.

(H 4.1): The higher the trade flows between a country pair in $t_{0}$, the more the environmental policies of both countries will converge in the period between to and $t_{1}$. 


\subsubsection{Other factors}

It is the central objective of this project to analyse the extent to which international economic and institutional interlinkages among countries lead to similarity increases in their environmental policies. In focusing on these factors, however, we do not imply that other convergence causes might not be relevant. In the following, we therefore specify the other explanatory factors of convergence mentioned in chapter 3 . This way, we are able to make a more comprehensive judgement about the relative explanatory power of the convergence causes in which we are primarily interested.

A first variable can be derived from the theoretical literature on policy diffusion, policy transfer and policy learning (cf. Holzinger and Knill 2005b; Simmons and Elkins 2004). Among others, emphasis is placed in these theories on two factors that facilitate the transfer and emulation of policies, hence leading to increases in crossnational policy similarity over time, namely cultural ties between countries (e.g., in terms of language or religion) and geographical proximity. These factors are expected to work even in the absence of strong international institutional interlinkages between countries. One important advantage of the pair approach is the possibility to directly include an index of cultural similarity in the quantitative analysis (see table A4.3 in the annex).

A second control variable refers to the well-documented relationship between the level of economic development of a country and the comprehensiveness and strictness of its environmental policy as expressed by the Environmental Kuznets Curve (see chapter 3). For the pair approach, we use an interaction variable of per capita income difference between two countries and absolute income figures. We use the GDP per capita of the poorer country in order to measure the economic development of a country pair. ${ }^{4}$

4 Taking the average income rate of both countries would lead to an inaccurate estimation for country pairs with a high difference in income levels. 
A third variable refers to the existence of domestic political demand for a comprehensive and stringent environmental policy. For the pair approach, the influence of green parties is measured by commonalities of a country pair regarding electoral success, membership in parliament, and participation in government of green parties (see table A4.3). A high score is attributed to a country pair if green parties are equally highly influential in both countries. As with income, we use an interaction variable that also includes the difference between the two countries.

A fourth control factor to be considered is environmental problem pressure. The effect of this factor is tested with two variables, the level of $\mathrm{CO}_{2}$ emissions per capita and population density. Although both are rather rough indicators, they should serve as general proxies for problem pressure through environmental pollution. To represent the common pressure in a county pair, the lower level of emissions and the lower figures for population density are included. Again, the difference between the two countries is accounted for by using an interaction term.

Fifth, we control for effects of pre-existing similarity of policies on convergence in later periods. Theories of policy convergence through transnational communication and learning emphasise that the degree of existing similarity for the number of earlier adopters of a policy) may influence the degree of convergence in the future (social emulation and herding effects; see chapter 3). Moreover, the presence of a 'saturation effect' can be assumed: if a group of countries has already very similar environmental policies, convergence towards each other will necessarily decrease over time.

These specifications of hypothesis $\mathrm{H} 5.1$ on the other variables developed in chapter 3 are summarised in the following. A list of all independent variables and their descriptive statistics is given in table A6.2.

(H 5.1.1): The higher the cultural similarity between a country pair, the more the environmental policies of both countries will converge. 
(H 5.1.2): The higher the common income level of a country pair and the more similar it is in $t_{0}$, the more the environmental policies of both countries will converge in the following periods.

(H 5.1.3): The higher the influence of green parties in a country pair and the more similar it is in $t_{0}$, the more the environmental policies of both countries will converge in the following periods.

(H 5.1.4): The higher the level of $\mathrm{CO}_{2}$ emissions per capita of a country pair and the more similar it is in $t_{0}$, the more the environmental policies of both countries will converge in the following periods.

The higher the level of population density of a country pair and the more similar it is in $t_{0}$, the more the environmental policies of both countries will converge in the following periods.

(H 5.1.5): The more similar policies of a country pair in to, the more the environmental policies of both countries will converge during the following periods, as long as the degree of similarity already reached is not yet very high.

\subsection{METHOD OF ANALYSIS}

In the following analysis of the empirical data we assess the influence of the explanatory factors on the changes in policy similarity between pairs of countries. The models basically refer to a pooled data set of three cross-sectional assessments of convergence for the 1970s, the 1980s and the 1990s. Each of the three cross-sectional models includes observations on 276 country pairs. As noted above, the dependent variable for all models refers to the change rate of policy similarity from the beginning of a decade to its end, indicated in percentage points (see table 6.3). We begin with the most encompassing dependent variable: the complete sample of forty environmental policies, including all eighty-nine items on the presence of a policy, on instruments and settings. The regression results for the pooled data and the encompassing dependent variable are presented in tables 6.5 and 6.6 . 


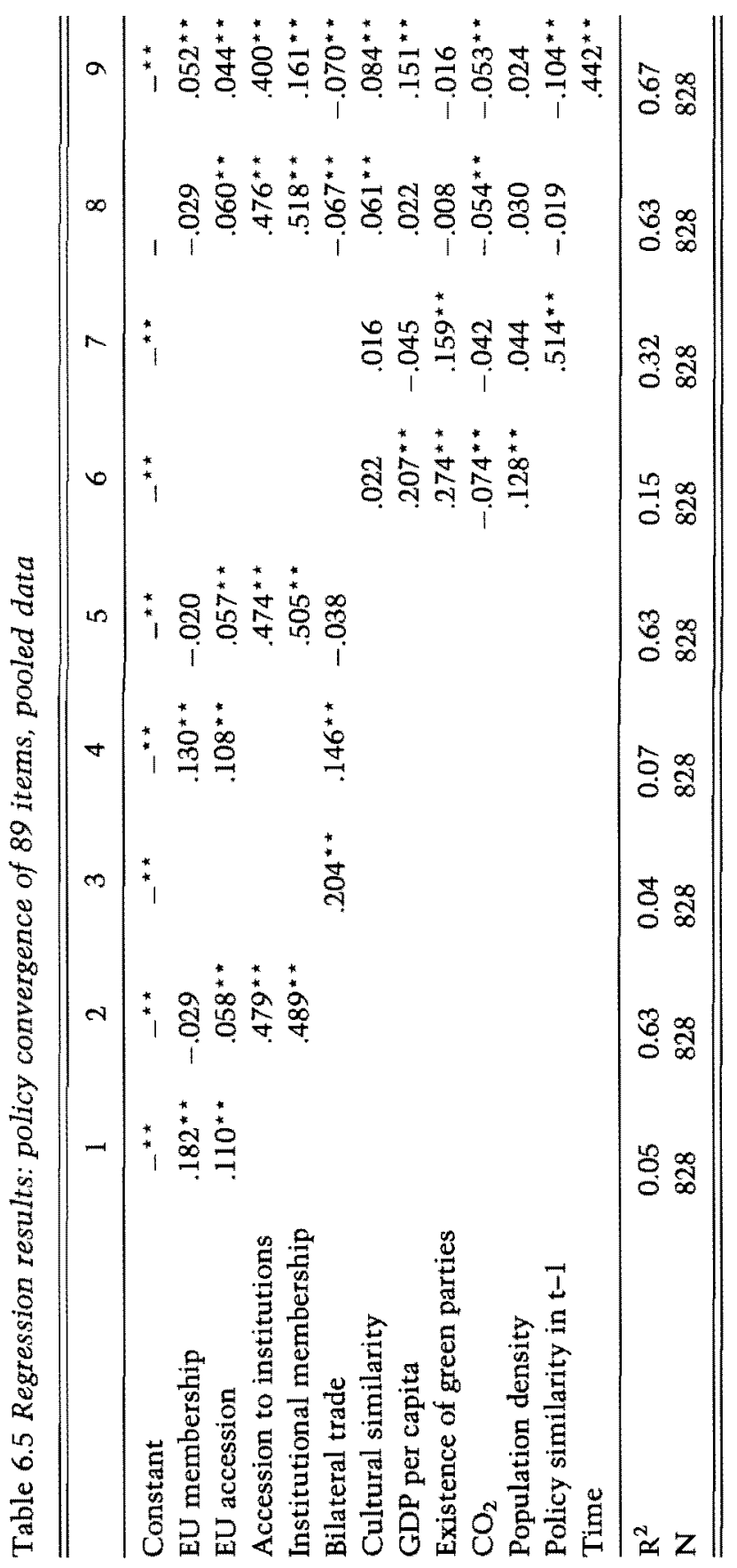




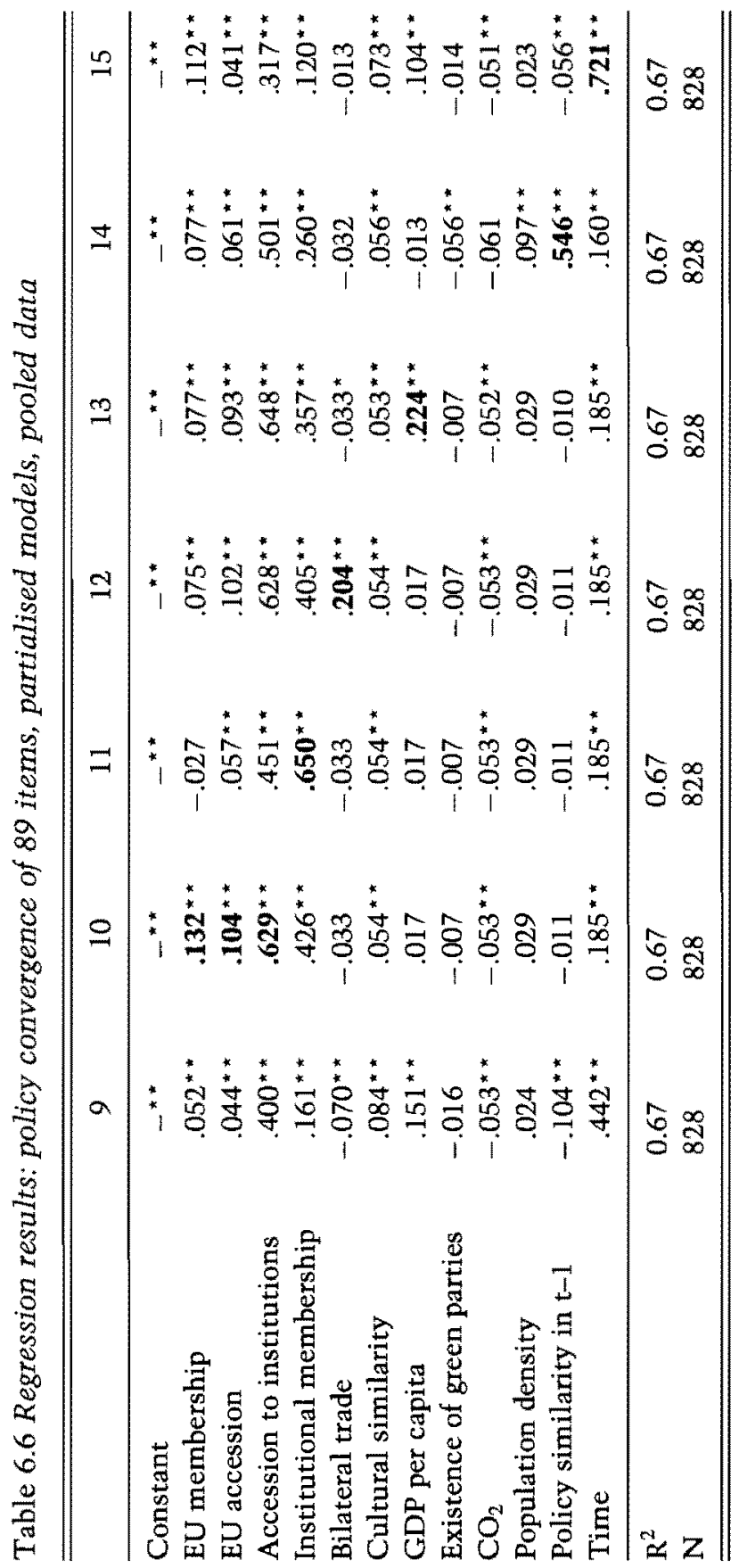


We apply simple regression models with standard OLS estimations. In order to answer the main research question on the influence of international driving forces behind growing similarity of domestic environmental policies, we use a stepwise approach. We start with regression models that show the explanatory potential of variables for institutional interlinkage (models 1 and 2, table 6.5) and for economic interlinkage (model 3) separately. Next, we provide two common models of these main variables, one including EU and trade effects, the other including all institutions and trade effects (models 4 and 5|. In a further step, the common explanatory power of all control variables is assessed in two models, the second one additionally including the pre-existing similarity of policies as an explanatory factor (models 6 and 7). Finally, all variables are taken together in one common model $(8)$. The last model $(9)$ adds a time variable. This procedure not only enables us to interpret the direction of the effects of the main independent variables, but also allows for assessing the importance of these explanatory factors relative to the set of control variables.

Through the inclusion of eleven independent variables and one time variable, we hope to get a model that is sufficiently specified, covering all major explanatory mechanisms. This set of variables, however, introduces statistical complications. We are confronted with the multicollinearity of independent variables, a problem that often emerges with this type of analysis. Trade figures, for example, correlate with EU membership, and wealthier countries can be assumed to be institutionally interlinked to a higher degree. In particular, some variables, such as the rise of green parties and the increase of institutional interlinkage, are highly correlated with time. This correlation of independent variables is hardly astonishing, as it is obvious that all institutional variables are endogenous factors; that is, they are themselves influenced by other factors, such as the level of economic development. Thus, some independent variables in the data set are correlated. Moreover, the variance in inflation statistics indicates problems for a robust estimation of coefficients. 
The methodological literature is divided over how to deal with multicollinearity. Whereas some propose to ignore it as long as results are significant, others propose various methods to control for it, and in particular, to search for ways of specifying the relationship among the variables (for an overview see chapter 13 in Kennedy 2003). We pursue an approach along the second road, trying to make multicollinearity among our independent variables visible and at least to give an impression of its extent and direction. Although the stepwise approach outlined above may already uncover changes in coefficients, and hence give information on multicollinearity, two further steps are undertaken in order to cope with this problem.

First, table A6.3 gives the bivariate regression coefficients of all independent variables with policy convergence. These figures can be interpreted as showing the maximum potential of each variable to explain the variance of the dependent variable, serving as a point of reference for the multivariate models.

The second step is displayed in table 6.6. For the models 10 to 15 , the common influence of covariates is systematically (i.e., sequentially) partialised out of the regression coefficients. That is, after bringing all variables into a hierarchical order, the common explanatory potential of two independent variables regarding the variance of policy convergence is attributed to the higher-ranking variable. Thus, all independent variables are orthogonalised: through bivariate regression and subsequent residualisation, they are made stochastically independent from each other. For subordinate variables in the order, only the unstandardised residual from the bivariate regression with their respective higher-ranking variables is included in the equation. This way we can speak of partialised or residualised models. The coefficient of a subordinated independent variable only includes information on effects which go beyond the (common) effect of higher-ranking covariates. This procedure allows for an assessment of the relative importance of the main variables compared to the other independent variables. This way, we capture the effects that go beyond the influence of international factors. The goodness of 
fit of the multivariate model is not affected by this orthogonalisation of independent variables.

The partialising out of effects of lower-ranking variables takes place stepwise. Variables are brought into an order and categorised into different groups. Each single variable is orthogonalised by all variables of higher-ranking groups. The procedure will be explained using the example of model 10 (table 6.6). The regression equation is given below:

$$
\begin{aligned}
y=c & +\beta_{1 y} x_{1}+\beta_{2 y} x_{2}+\beta_{3 y} x_{3}+\beta_{(4-123) y} x_{4-123} \\
& +\beta_{(5-1234) y} x_{5-1234}+\beta_{(c i-12345) y} x_{c i-12345} \\
& +\beta_{(t-12345 c i) y} x_{t-12345 c i}+e
\end{aligned}
$$

In this basic version of the partialised regression, five different groups for orthogonalisation are composed by the following twelve variables: variables $x_{1}$ to $x_{3}$ are harmonisation variables (group one), $x_{4}$ is communicative potential (group two), $x_{5}$ is trade (group three), $x_{c i}$ represents the control variables $c_{i}$ (group four) and $x_{t}$ the time variable (group five).

The hierarchical order chosen in model 10 implies the following theoretical expectations / that is, variables are ordered as if we expected ..... First, the expectation is that the strongest effects on environmental policy convergence arise from international harmonisation. Second, it is assumed that convergence effects of communication will be somewhat weaker than harmonisation effects, thus 'institutional membership' follows after the harmonisation variables. Third, the trade variable is expected to have even weaker effects. For the other variables /cultural similarity, income, political demand, problem pressure and pre-existing similarity of policies] we are not primarily interested in their contribution to the explanation of convergence, but in a potential effect that might go beyond the main variables. Thus, they are ranked lower in order. Except for the time variable, we do not differentiate between the control variables; all of them are residualised on the five variables referring to the three main driving forces of convergence. The time 
variable is the last one, as it is correlated with many covariates and no explicit theoretical expectation can be formulated. This way only the time effect that goes beyond the influence of all other variables enters the regression. Its coefficient is thus expected to be much lower than in the non-partialised model.

In addition to model 10 with the harmonisation variables at the top of the ranking, five other partialised regression models are run with different hierarchical orderings, implying different theoretical expectations. This way we avoid arbitrariness in choosing the hierarchy of variables, as we do not possess a confirmed theory telling us which factor is the most relevant. At the top of the rankings in models 11 to 15 are the communicative potential variable, the trade variable, and those control variables that are most important according to bivariate regression (table A6.3), i.e., the level of economic development, pre-existing similarity, as well as the time variable. The equation is similar to the one for model 10 . In table 6.6, the variable in the highest rank is marked in bold for each model.

So far, all models are based on the most encompassing dependent variable including all forty policies. These models are complemented by others with different dependent variables for the various sub-groups of policies of theoretical interest (as developed in chapter 3 and section 6.3). They also serve as a further test of robustness for the estimated effects of the explanatory variables (see table 6.7).

Moreover, the pooled model will then be compared to the crosssectional ones (table 6.8). This way we can compare causal effects in the decade models with effects over the whole period and draw conclusions on the changing importance of causal mechanisms over time. The analyses thus provide more differentiated and more reliable results. For the models in tables 6.7 and 6.8 , we use the partialised model 10 as a basis. The reason for this choice is that the harmonisation variables in group one show not only the largest effect in model 10, where they are ranked highest, but also turn out to be very important in all other partialised models. 


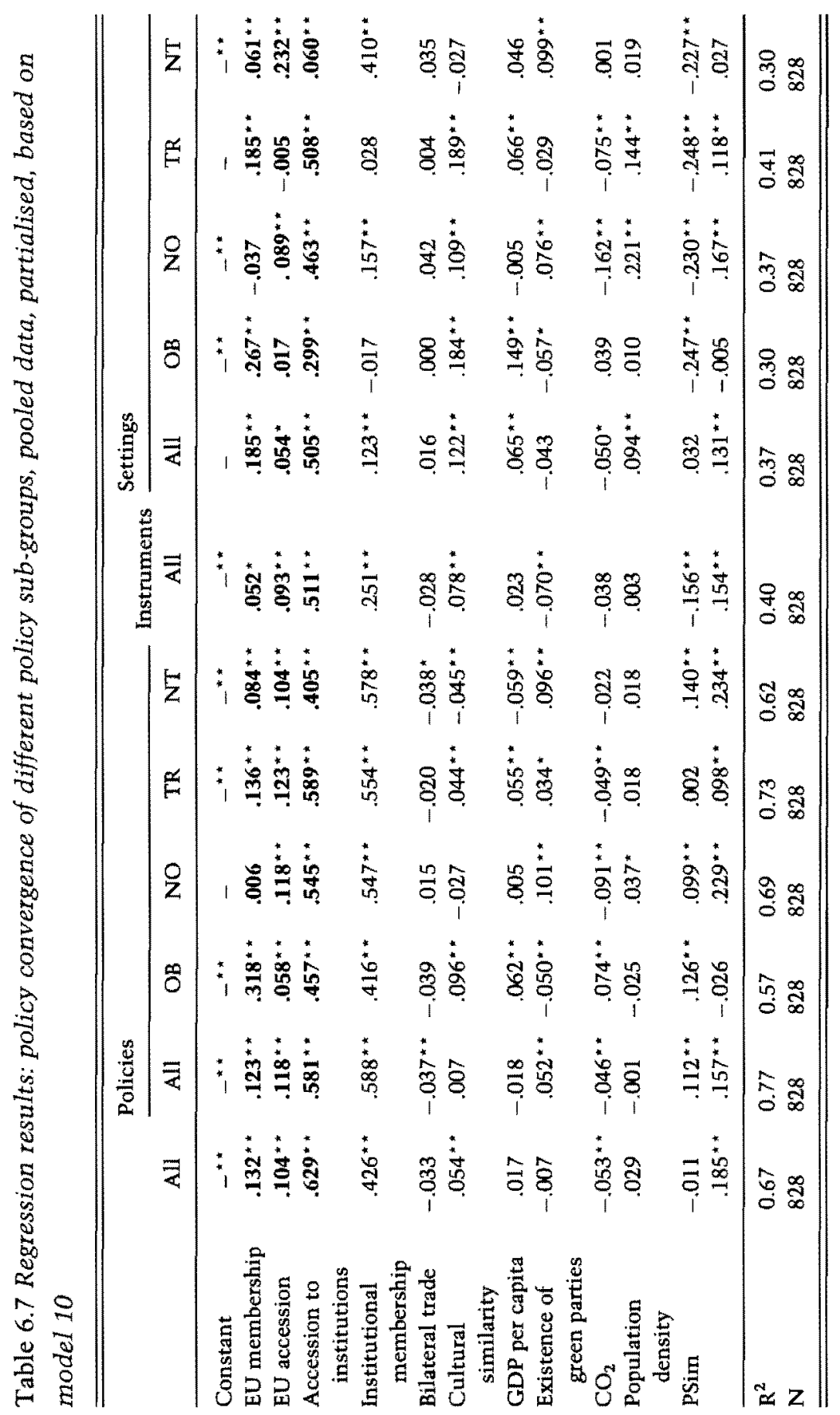


Table 6.8 Regression results: policy convergence of 89 items, pooled data and decades, based on model 10

\begin{tabular}{|c|c|c|c|c|}
\hline & All & $1970 \mathrm{~s}$ & $1980 \mathrm{~s}$ & $1990 \mathrm{~s}$ \\
\hline Constant & $-{ }^{* *}$ & $-{ }^{\star \star}$ & $-{ }^{\star *}$ & $-{ }^{* *}$ \\
\hline EU membership & $.132 * *$ & $.326^{\star *}$ & .063 & $.165^{* *}$ \\
\hline EU accession & $.104^{\star \star}$ & -.093 & $-a$ & .062 \\
\hline Accession to institutions & $.629^{* *}$ & $.383^{\star *}$ & $.564^{* *}$ & $.435^{* *}$ \\
\hline Institutional membership & $.426^{\star \star}$ & $.103^{\star \star}$ & $.197^{\star \star}$ & .003 \\
\hline Bilateral trade & -.033 & $.125^{\star *}$ & -.009 & -.055 \\
\hline Cultural similarity & $.054^{* *}$ & $.083^{\star}$ & $.192^{\star \star}$ & .021 \\
\hline GDP per capita & .017 & $.228^{* *}$ & $.179^{\star \star}$ & $.092^{\star}$ \\
\hline Existence of green parties & -.007 & $-b$ & -.004 & -.039 \\
\hline $\mathrm{CO}_{2}$ & $-.053^{* *}$ & .049 & $-.112^{* *}$ & $.099^{*}$ \\
\hline Population density & .029 & .019 & $.224^{\star \star}$ & $-.151 * *$ \\
\hline PSim & -.011 & $.105^{\star}$ & $-.318^{\star *}$ & .024 \\
\hline $\mathrm{R}^{2}$ & 0.67 & 0.34 & 0.51 & 0.20 \\
\hline $\mathrm{N}$ & 828 & 276 & 276 & 276 \\
\hline
\end{tabular}

Note:

a No accession during the 1980s, as accession negotiations with Spain, Portugal and Greece started before 1980 [see chapter 4].

b No green parties before 1980 .

\subsection{FINDINGS}

\subsubsection{Overall model fit}

Tables 6.5 to 6.8 present the results of the regression analysis. The models show satisfying results for the overall explanation of variance and the fit of the model. For the pooled model that includes all explanatory variables [table 6.5, model 9], referring to the whole eighty-nine policy-item sample, the degree of explained variance is very high, with corrected $r^{2}$ of .67 . The explanatory potential of mode1 5 that includes only the main project variables shows a high fit as well $\left.\mid r^{2} .63\right)$, confirming their high relevance for the process of sigma-convergence. On the other hand, the stepwise approach demonstrates that the contribution of the control variables is rather limited. Model $6\left(\mathrm{r}^{2} .15\right)$ and model $7\left(r^{2} .32\right)$ including solely the control variables present a less 
efficient estimation of policy convergence. The latter includes the level of pre-existing similarity of policies between countries.

Differences regarding the goodness of fit occur when we look at sub-groups of environmental policy. The degree of explained variance is on average slightly higher than for the overall sample of policies if only the convergence of the presence-of-policy items is regarded $\left(\mathrm{r}^{2} .57\right.$ to .77 in table 6.7$) . \mathrm{R}^{2}$ is significantly lower for the convergence of policy instruments $\left(\mathrm{r}^{2} .40\right)$ and for policy settings $\left(\mathrm{r}^{2} .30\right.$ to .41$)$.

The fit of the model also varies strongly if the three decades are analysed separately. Table 6.8 shows that the explanatory potential of the model for convergence between 1980 and 1990 is rather high $\left(\mathrm{r}^{2} .51\right)$. It is less for the 1970s $\left(\mathrm{r}^{2} .34\right)$ and even lower for the $1990 \mathrm{~s}$ $\left(r^{2} .20\right)$. This variation can be related to changes in the effectiveness of some causal mechanisms. The difference from the pooled model is caused by a parallel development over time of the dependent variable and some crucial independent variables that leads to a much higher correlation than for the cross-sectional approach.

In the following sections the results of the regression analysis are presented separately for each of the explanatory factors. For the main independent variables we proceed in the following way. First, we analyse the effects for the whole policy sample for each variable. Second, we differentiate between policy sub-groups. Third, we compare the effects for the different decades under study. For the control variables we are less systematic and present only the most interesting results. Sometimes reference is made to bivariate correlations (cf. table A6.3 in the annex).

\subsubsection{International harmonisation}

We start with the variables relating to international harmonisation. While international harmonisation is generally of great importance across all explanatory models, differences exist with respect to the three variables which are supposed to represent this mechanism: common EU membership, EU accession and the accession to other international institutions. 
EU membership Model 1 in table 6.5 illustrates the results for the impact of EU membership on convergence of environmental policies. The effect of harmonisation among member states confirms the expectation from hypothesis $\mathrm{H}$ 2.1.1: EU membership is positively correlated with changes in policy similarity (.182). The EU effect, however, is not as dominant as one would expect. The models including all variables show that, although significant, EU membership is not the strongest predictor of convergence, not even for obligatory policy items. In model 9 , the standardised coefficient declines to .052 , whereas the coefficient is .132 in the partialised model 10 , where the common explanatory potential of EU and other covariates is totally assigned to EU membership.

Table 6.7 validates the expectations with regard to varying EU effects for different policy types. EU membership has a strong positive effect on the convergence of obligatory presence-of-policy [.318) and obligatory setting items $(.267)$, i.e., on convergence of policies where binding regulations exist at the international level. On the other hand, there is no significant effect for convergence of non-obligatory policies and settings, a cross-check which confirms the validity of this indicator. The difference in the EU effect for changes in similarity of trade-related policy items points in the same direction. They are higher for trade-related presence-of-policy items (.136) and setting items $(.185)$ than for the group of non-trade-related policies (.084) and settings (.061). This result is consistent with the fact that environmental policy at the European level has been strongly influenced by the concern for the creation of a common market (Holzinger 1994; Knill 2003). Finally, while the effect is similar for settings and for policies, it is much weaker when it comes to policy instruments $(.052$, table 6.7$)$.

The correlation between EU membership and convergence also varies over time (table 6.8). The general impact of EU membership is strongly positive for the 1970 s $(.326)$ and, to a lower degree, for the 1990s [.165), but very weak for the 1980s (.062). This observation is in line with what is known about the development of EU 
environmental policy. For the 1970 s, the increasing environmental activities of the EU caused strong convergence effects for its members. ${ }^{5}$ During that time, the EU introduced binding regulation on nine out of nineteen obligatory policies in our data set /see table 4.1 in chapter 4), whereas only two additional directives that refer to four items of our selection of policies were introduced between 1978 and 1990. Thus, except for changes in existing legislation, almost no additional harmonisation pressure emerged at the European level. From 1990 until 2000, however, five directives and regulations relating to six items were launched by the EU, which explains the higher effect on convergence observed for the 1990s.

What are the reasons for the surprising lack of predominance of EU membership? First, until 1990 only twelve countries were members of the EU, and, for the two decades before, significantly less than half of the sample. Second, non-member countries oriented their policy towards EU legislation. ${ }^{6}$ Third, our data show significant differences between EU member states due to discrepancies in implementation, as environmental directives usually leave considerable leeway to domestic policy-makers. ${ }^{7}$ Finally, in the case of minimum harmonisation, one would not expect total convergence among EU member states anyway.

EU accession Also EU accession and prospective membership show effects on policy convergence (H 2.1.2). In model 1 (table 6.5), a positive correlation can be observed that is slightly weaker (.110) than the one for EU membership. This proportion can be found almost across all models, e.g. in model 10 in table $6.6(.104)$.

${ }^{5}$ EU member states at the beginning of the 1970s: Belgium, Denmark, France, Germany, Ireland, Italy, Netherlands, UK.

${ }^{6}$ Austria and Switzerland, for example, applied the same limit values for sulphur content in gas oil as the EU during the 1980s.

7 For example, Germany and the Netherlands had different car emission standards in 1980 in spite of being subject to the same EU requirement. 
The clear difference between accession effects on convergence of the presence-of-policy items and convergence of setting items is striking. The latter is very low and barely significant. A plausible explanation for this difference might be that candidate states broadly implemented the environmental acquis, but lagged behind most other member states with respect to the level of policy settings before entering the Community. There is no such difference between the effects on convergence of obligatory policies and non-obligatory policies.

The separate analysis for each decade sheds light on the dynamics of EU accession effects. For the 1970 s a negative though not significant effect has been found (-.093). Greece, Portugal and Spain are responsible for this effect. This implies that they did not implement the environmental acquis already from the beginning of the accession talks in 1978 but only after actual accession. The coefficient for accession during the 1990s is positive (.062), however not very accentuated. This could be the consequence of the two enlargements during the 1990s, the EFTA enlargement and the beginning Eastern European enlargement process. In this decade there are two groups of accession candidates: the Scandinavian states and Austria for the early 1990s, and the CEE states Poland, Hungary, Slovakia, Bulgaria and Romania. A differentiation between the two groups showed that for the first group, there is even a negative effect, while for the second, a more pronounced positive effect can be found. The EFTA countries already had environmental policies similar to the EU members; thus, there was almost no potential to converge any further for this group, whereas for the CEE countries the accession process produced significant convergence.

Accession to institutions In hypothesis $\mathrm{H} \mathrm{2.1.3,} \mathrm{we} \mathrm{expect} \mathrm{that}$ international harmonisation can also be effective through the accession to international institutions other than the EU. Our results show that this variable does a very good job at explaining convergence. The variable's influence is clearly stronger than the influence 
of EU variables. In model 2 (table 6.5 ) the coefficient shows the expected positive sign (.479). The size and direction of the effect are quite robust. This can be seen in model $9(.400)$ that includes the whole set of variables. This indicator of the degree to which national governments are subjected to international hard law seems to be a very precise predictor of policy convergence. This is not surprising, as the variable is a fine-tuned indicator of institutional interlinkage. In spite of its explanatory power, this variable should not be seen as too close to the dependent variable in causal terms: there are many steps from the adoption of international agreements to the domestic implementation of these agreements and therefore many obstacles to overcome. The two variables are not interchangeable and their relation is thus not tautological.

A very pronounced positive effect does not only exist for convergence of all policy items, but also for the majority of policy subgroups. We find only minor differences regarding the effects on the convergence of settings, instruments and presence of policies, with a somewhat higher coefficient for the latter. The influence of accession to international institutions is insignificantly low only for non-traderelated settings, where the regression model in general shows a lower fit. Finally, the explanatory potential of this variable seems to be lower for obligatory policies and settings, whereas it turns out to be a powerful predictor for non-obligatory settings and policies.

More variation exists regarding the accession effects over time (table 6.8). For the convergence of all items in our data set, coefficients are lowest for the 1970s (.383), and higher for the 1980s (.575) than for the 1990s [.435). The weaker effect during the 1970s, as well as the peak in the second decade, can be traced back to the fact that many international environmental regimes like the Convention on Long-Range Transboundary Air Pollution or the Vienna Convention for the Protection of the Ozone Layer entered into force after 1980. The slight decrease of the positive effect for the 1990s may be a result of the high level that institutional integration had already reached in our country sample. 
In general, international harmonisation turns out to be an influential mechanism for the occurrence of policy convergence from 1970 to 2000 . This effect is the dominant one for the regression model 9 in table 6.5 that includes all independent variables. Therefore, the partialised version with all other variables orthogonalised according to harmonisation variables, i.e., model 10 in table 6.6, was chosen for the presentation of further regression models for single decades and for policy sub-groups in tables 6.7 and 6.8. Harmonisation effects may be overestimated with respect to their absolute size in these models; however, not with respect to their relative size.

\subsubsection{Transnational communication}

Our regression results not only indicate strong convergence effects resulting from international harmonisation, but also provide support for the expected impact of communication and information exchange in transnational networks (H 3.1). The effect of common membership in international institutions on cross-national policy convergence as an effect of international interlinkage that cannot be linked to the outcome of international law is - with a standardised coefficient of .489 (model 2 in table 6.5 ) - comparable in size to the influence of international harmonisation. It only decreases in model 9 with the inclusion of time (.161), although it keeps its positive sign and is still significant. Obviously, the influence of communicative networks increases over time. Model 11 in table 6.6 shows the variable's maximum explanatory potential in a partialised multivariate model 1.650); all other coefficients can be interpreted only in terms of their effect beyond the effect of membership in international institutions. It turns out that here the harmonisation variables explain less. Model 10 shows that the strong positive influence persists (.426), even when only the effects of common institutional membership are included that go beyond harmonisation.

Differences can be observed for the effect of common institutional membership on sub-groups of policies. In table 6.7, transnational communication effects seem to be most pronounced for 
the convergence of presence-of-policy items (.588). It is only half as strong for the convergence of instruments $(.251)$ and even weaker for the convergence of setting items $(.123){ }^{8}$ These results are in line with our theoretical expectation for the role of transnational communication. It is not surprising that transnational communication through institutional networks exerts a higher influence on the approximation of policy repertoires and on the diffusion of broader ideas of policies than on the exact similarity of a policy setting.

Moreover, coefficients are higher for non-obligatory and nontrade-related policy items. On the other hand, for the convergence of obligatory as well as for trade-related setting items, there is no significant communication effect exceeding the one of harmonisation variables. This shows that the effect of communication relates especially to 'voluntary' convergence not caused by international interdependencies and international harmonisation. It need not constitute a contradictory finding that transnational communication plays an important role for the convergence of obligatory presenceof-policy items. For instance, it is rather plausible that policies adopted at the level of the EU might receive broader international attention, hence fostering the spread of these policies also between those countries that are not (yet) EU member states. It should be noted that until 1990, only 30 per cent of all country pairs shared EU membership. Moreover, countries that are interlinked for a longer time might introduce obligatory policies more quickly.

The influence of common membership also varies across decades. For the 1970s [.103) and 1980s [.197), this variable makes a positive contribution to the explanation of convergence of all policy items (table 6.8 and table A6.3). For the 1990s, however, this effect disappears completely. This striking change in the effects of transnational communication can be explained by the interaction of two developments. On the one hand, it is conceivable that country

\footnotetext{
- This difference holds for the bivariate relation as well and is not caused by the multivariate orthogonalised version (see table A6.2).
} 
pairs with strong communicative interlinkage, due to saturation effects, converged to a lesser extent during the 1990s than in earlier periods. If one looks at the degree of similarity of the policy repertoires already reached before the 1990s (see the effect on presenceof-policy above), it becomes clear that communication did not affect the growing together of those countries in the 1990s. On the other hand, our data showed that country pairs characterised by weak communicative interlinkage strongly converged during the 1990s. It should be remembered that this variable includes information on the length of membership - countries that only recently acceded to international institutions weigh less. This holds true in particular for the CEE countries where convergence was driven by harmonisation effects emerging from the accession to international institutions.

What can be said of the explanatory potential of this variable in general? Obviously, it confirms that there are institutional effects beyond harmonisation. Common membership in institutions with high communicative potential is one of the most influential factors in order to account for similarity increases. However, a direct attribution of these effects to voluntary processes of learning, policy transfer or diffusion is not easy, as we do not trace single processes. Nonetheless we found that communication effects have been particularly pronounced for items that are either non-obligatory or not related to trade, as well as higher coefficients for the presence of policies than for instruments and precise settings.

\subsubsection{Regulatory competition}

Just like the other main explanatory variables analysed so far, convergence effects through regulatory competition confirmed theoretical expectations from hypothesis $\mathrm{H} 4.1$ in general. It can be stated that for a pair of countries, a high degree of economic interlinkage leads to increasing similarity of domestic policies. In model 3 in table 6.5 the correlation between bilateral trade openness and convergence is significant and clearly positive (.204). 
As many empirical studies did not find support for such a trade effect on convergence or diffusion /cf. Drezner 2001; Potoski 2001; Simmons and Elkins 2004), this result should be interpreted carefully for two reasons. First, it should be noted that the trade effect disappears in more comprehensive models; the coefficient is even slightly negative in model $8(-.070)$. A second caveat comes from the comparison of partialised models 10 and 12 in table 6.6, where the former are orthogonalised with harmonisation variables in first order, the latter with bilateral trade. It is obvious from theoretical considerations that there will be some endogenity between economic interlinkage and institutional integration, in particular in the EU: institutional integration leads to increased trade flows, and the existence of economic interlinkage is a strong incentive to cooperate in political institutions at the international level. Our results suggest that the latter factor is more important than the first. While there is no trade effect beyond harmonisation and communication in model $10(-.033)$, the coefficients for institutional variables are relatively stable regarding their subordination to trade openness in model 12. This supports the conjecture that the influence of competition is less important and overridden by institutional integration. It seems plausible that potential competition effects were anticipated by the involved countries and subsequently reduced by international harmonisation. EU environmental policy was to a large extent based on market integration: member states aimed at the creation of the internal market; however, they were interested in the correction of market results by environmental regulation as well. This paved the way for harmonisation of trade-related environmental problems. This interpretation is supported by our descriptive results, showing that convergence was much stronger for trade-related rather than non-trade-related items (see section 6.4).

Regardless of the absolute influence of bilateral trade openness, differences in its relative influence in sub-group models are of interest. It is striking that for no group of policy items do we find a significant influence of bilateral trade openness on increasing 
similarity (table 6.8). In particular, trade effects found for the convergence of trade-related policies and settings are not more pronounced than for their non-trade-related counterparts, neither for the partialised models in table 6.6, nor for bivariate regression (table A6.3).

However, differences exist with regard to trade effects over time, confirming the interpretation that competition seems to be substituted by regulatory cooperation and transnational communication. Trade effects that go beyond harmonisation and cooperation are pronounced and significantly positive for the 1970s 1.125; see table 6.81, when international cooperation in environmental policy has just started. This effect completely disappears over time, and for the 1990s, the model shows a negative relation between economic interlinkage and convergence $(-.055)$, which is confirmed at the bivariate level as well $(-.097$, table A6.3). Thus, for convergence in recent years, trade dependence seems to play a minor role.

\subsubsection{Other variables}

Our findings in model 6 (table 6.5 ) show that other variables than the ones discussed above contribute to the explanation of policy convergence in the environmental field. Most of them have significant effects, if the main variables are left out.

Cultural similarity We hypothesised that cultural similarity constitutes an influential factor for the occurrence of policy convergence $(\mathrm{H}$ 5.1.1). As shown in the bivariate regression in table $\mathrm{A} 6.3$, this expectation is confirmed. There is a positive influence on convergence of environmental policies except for the 1990s, where increasing policy similarity is less linked to culturally similar and neighbouring countries. The partialised models in tables 6.6, 6.7 and 6.8 show that the influence of cultural similarity beyond the main variables under investigation is rather limited.

We find significant positive effects for the convergence of setting items (.122), for convergence in the 1970s (.082) and, most pronounced, in the $1980 \mathrm{~s}(.192)$. The strong effects of cultural 
similarity during the 1980 s are observed in a period that is characterised by a strong expansion of environmental policies, both at the European and the national level. It is well conceivable that this dynamic development particularly inspired countries to transfer and copy innovative policies from other countries. This interpretation is supported by the fact that for the 1990s /which is generally seen as an era of environmental policy stagnation) cultural similarity is not a relevant causal factor behind convergence. This development goes along with the increasing importance of international institutions and seems to become substituted by harmonisation. The increasing similarity of domestic environmental policies is not limited to neighbourhood effects any more. Astonishingly, cultural similarity effects are also strong for obligatory policies. As this cannot be attributed to EU effects (this is excluded because of the partialisation), the explanation might again be found in the emulation of EU policies by culturally similar countries that were not yet EU member states.

Income In the literature, environmental policy is often related to the wealth of a country. With regard to the impact of economic development, we find support for our hypothesis H 5.1.2 that a high and similar level of income of a country pair leads to convergence. We observe positive income effects on convergence in the bivariate analysis $(.225$, table A6.3) and a positive effect in model 9 that includes all variables (.151, table 6.5). However, the coefficients decrease strongly when it comes to effects beyond institutional interlinkage. Comparing partialised models 10,11 and 13 in table 6.6, the same can be said as for regulatory competition above. Whereas institutional effects are robust in model 13 that is orthogonalised by the income level, income effects disappear in models 10 and 11. Again this can be interpreted as the non-existence of an independent effect of economic development on convergence.

A second parallelism to trade effects is the fact that we find positive influence on convergence independent from institutional effects only for the first and second decade, but not for the 1990s. 
Here bivariate regression even reports a strong negative correlation $(-.160)$. The negative correlation is a consequence of two developments: rich countries were already very similar and did not converge any further, whereas poor countries converged during the 1990s (see the descriptive results in chapter 5).

Green parties The expectations on the influence of political demand on cross-national policy convergence (hypothesis $\mathrm{H}$ 5.1.3) are partially confirmed. The rise and success of green parties had a significant positive effect at the bivariate level for the $1980 \mathrm{~s}(.182)$ and 1990 s (.074, table A6.3), but not for the 1970 s because green parties did not exist in that period. This influence is, however, not visible when all other variables are included (model 9 in table 6.5).

The only policy sub-group models where the effect goes beyond the influence of the main variables under study are those for convergence on non-obligatory and non-trade-related items itables 6.7 and A6.3|. Thus we find effects on convergence of policy items that are less linked to international interdependence and harmonisation which is in line with the expectation that political demand affects domestic policy choice. In general, however, political pressure from environmentalism does not seem to be an independent complementary mechanism that has influenced cross-national policy convergence in recent years.

Environmental problem pressure A similar conclusion can be drawn for the two variables measuring environmental problem pressure (H 5.1.4). Over time, both add little to the explanation. Almost all multivariate and pooled models show only minor or no explanatory power. A closer look, however, gives a more differentiated pattern. As can be seen from tables 6.7 and A6.3, the expected positive effect of high and similar $\mathrm{CO}_{2}$ emissions appears in two models: for obligatory presence-of-policy items (.074) and for setting items (.039). Together with the fact that $\mathrm{CO}_{2}$ emissions have been influential especially in the first decade (tables 6.7 and A6.3), this result points 
at a pattern of substitution between the mechanism of domestic problem pressure and international harmonisation: high problem pressure mainly in the field of air pollution led to the introduction of environmental policies, and subsequently international regulation followed at the end of the 1970s and during the 1980s, leading to a decrease in coefficients. A positive $\mathrm{CO}_{2}$ effect reappears during the 1990s. This can be causally linked to the catching-up of CEE countries where environmental problem pressure was high before, although without consequences on policy-making.

The influence found for population density is slightly higher, though not as strong as expected. A very strong positive effect beyond international factors is only present for the convergence of nonobligatory (.221) and trade-related (.144) setting items. In both groups we find a large share of policies directed towards water pollution, which commonly appears more often in densely populated areas.

It should be recalled that the pair approach aims at explaining sigma-convergence and not at explaining the direction of environmental policy. Given this, it is no surprise that the effects of a common level of income or commonly experienced problem pressure diminish over time. First, these factors are gradually substituted by international harmonisation. Second, the main aspect we measure with the pair approach is the introduction of policies. As for presenceof-policy and instruments, we usually observe not many changes over time; further changes of policies are only captured by the setting dimension. The big effects, however, are caused by the introduction of policies. Therefore, convergence effects shrink over time, as they are less pronounced in the database in later periods.

Pre-existing similarity of policies For some variables discussed so far, we observed that their influence seems to change in the 1990s. This interpretation can be advanced in interpreting the change in the pattern of convergence as a consequence of saturation effects: convergence between some countries already reached a high level in the 1980s (e.g., for Germany and Switzerland, as shown in figure 6.3). 
Those country dyads did not have much potential to converge any further in the following period.

In order to test the saturation effect $[\mathrm{H} 5.1 .5]$, we use a variable that consists of the level of similarity between country pairs in the previous period. In the bivariate analysis we find a very high positive correlation of this variable with convergence (.546; see also model 7 in table 6.5). This suggests that those country pairs that already have a high degree of similarity of their environmental policies subsequently converge more strongly than country pairs that are more dissimilar. In the general multivariate model, however, this effect disappears or even turns negative (models 9-10), and no independent effect is found that goes beyond the influence of international driving forces of convergence (models 10-12 in table 6.6).

The analysis by decades confirms the expectation of a saturation effect. In the bivariate analysis for all items, a strong positive correlation is found for the 1970 s, followed by a weak positive effect in the 1980s and a significantly negative one for the 1990s (table A6.3). This decreasing effect is roughly confirmed in the multivariate partialised model (table 6.8). This effect can be explained as follows: pioneer countries, i.e., those countries which already had policies in place in 1970, became more similar during the 1970s. Consequently, in the next decades their potential to further converge shrank. At the same time, those countries which were dissimilar before show much higher convergence rates in the $1990 \mathrm{~s}$. That is, convergence is now better explained by previous dissimilarity. This turn can be ascribed to the fundamental changes in the environmental policies of the CEE countries and Mexico. Therefore, the negative correlation for the 1990 s indicates a process of catching-up of the laggard countries.

Time As already mentioned above (section 6.6.1), time also influences convergence. We do not have explicit theoretical expectations about this variable. It represents the dynamics of this relatively new policy area and it includes various aspects that drive the development of environmental policy in general, which have not been 
included in this analysis, such as technological progress, diminishing costs of environmental protection, and external shock events like acid rain and 'Waldsterben', the nuclear disaster in Chernobyl, or the concerns about the greenhouse effect.

Time is highly correlated with policy convergence, even for the overall model 9 in table 6.5 (.442). For the partialised models (table 6.6$)$ the effect is still significantly positive $(.185$, models 10-13). Model 15 shows the time factor has a very strong effect if all other factors are partialised out (.721) - actually, time has the strongest bivariate effect of all variables (table A6.3). Still, even in this model harmonisation, transnational communication and income have some explanatory power. The effect is largest for accession to institutions (.317), followed by institutional membership (.120) and EU membership (.112).

\subsection{CONCLUSION}

The statistical analysis of sigma-convergence of environmental policies on the basis of the pair approach largely confirmed the expectations and the specific hypotheses developed in section 6.4, although there are some surprises when it comes to the exact size of the effects.

First of all, at the descriptive level we saw that the similarity of environmental policies of the twenty-four countries has much increased over the observed period from 1970 to 2000 . Therefore, with respect to the first main question of this research project a clear answer can be given: there is no doubt that environmental policies converged to a considerable extent. The picture of sigma-convergence resulting from the analysis of country pairs is much clearer and less ambiguous than from the country-based aggregate analysis in chapter 5 .

Second, the extent of convergence varies according to the dimension of policy. Convergence is most pronounced when we look only at the presence of a certain policy. It is less strong when we look at the similarity of the instrument used, and it is even 
weaker when it comes to the exact setting of an instrument, such as limit values for emissions or environmental taxes. Moreover, convergence is more pronounced for obligatory and trade-related policies than for non-obligatory and non-trade-related policies.

Third, among the three main causal factors, international harmonisation contributes most to the explanation of convergence. The mechanism of international harmonisation was operationalised by three variables: EU membership, EU accession and accession to international environmental organisations other than the EU. These differentiations lead to a surprising result: accession to and membership in the EU explains clearly less than accession to other international environmental institutions. It is somewhat counterintuitive that the effects of EU harmonisation on the environmental policies of mostly European countries are smaller than the effects of harmonisation by multilateral international treaties. This result can, however, be explained by the fact that, seen over the whole period, EU members form only a small part of the country sample.

Fourth, the effects of transnational communication on environmental policy convergence are almost in the same order of size as the effects of international harmonisation. Although we did not formulate a hypothesis on the comparative effect of these two mechanisms, it seemed more intuitive that harmonisation effects are stronger than communication effects. However, it turned out that communicative interaction has similarly strong effects on the convergence of environmental policies as harmonisation. The effect of transnational communication on convergence is particularly pronounced with respect to non-obligatory and non-trade-related policies. This is in line with expectations: when there is already a harmonised policy at the international level, there is not much room left for transnational communication to influence further convergence. The effects of transnational communication seem to vanish during the 1990 s. This may be a consequence of saturation effects on the side of countries characterised by high communicative interlinkage. 
Fifth, the explanatory potential of the mechanism of regulatory competition is less convincing than that of international harmonisation and transnational communication. Although there is a clear and significant trade effect in a bivariate regression model, the effect vanishes in multivariate models and in models that subordinate the trade variable to harmonisation or communication. This implies that there is no effect of regulatory competition that goes beyond the effects of harmonisation or communication. Moreover, the effects of trade are no more pronounced for trade-related policies than for those not related to trade.

Sixth, the other variables controlled for in the project to some extent contribute to the explanation of environmental policy convergence. Most pronounced are the effects of income and cultural similarity, whereas political demand and environmental problem pressure show weaker effects. The latter two do not seem to play an independent role for the explanation of convergence. The introduction of the variable 'pre-existing similarity' showed that countries with previously similar policies converged more strongly in subsequent periods. Whereas this effect is particularly strong for the 1970s, it is weaker during the 1980s and turns negative during the 1990 s due to saturation.

In sum, we find that the environmental policies of the twentyfour countries in the sample converged to a great extent in the period from 1970 to 2000 . Convergence is mainly caused by two mechanisms, namely international harmonisation and transnational communication. Regulatory competition and some domestic variables play a minor role in the explanation of environmental policy convergence. 